\title{
An Edge-Based Smoothed Finite Element for Free Vibration Analysis of Functionally Graded Porous (FGP) Plates on Elastic Foundation Taking into Mass (EFTIM)
}

\author{
Trung Thanh Tran, ${ }^{1}$ Quoc-Hoa Pham $\mathbb{D}^{2,3}$ and Trung Nguyen-Thoi ${ }^{2,3}$ \\ ${ }^{1}$ Department of Mechanics, Le Quy Don Technical University, Hanoi, Vietnam \\ ${ }^{2}$ Division of Computational Mathematics and Engineering, Institute for Computational Science, Ton Duc Thang University, \\ Ho Chi Minh City, Vietnam \\ ${ }^{3}$ Faculty of Civil Engineering, Ton Duc Thang University, Ho Chi Minh City, Vietnam
}

Correspondence should be addressed to Quoc-Hoa Pham; phamquochoa@tdtu.edu.vn

Received 31 December 2019; Revised 10 March 2020; Accepted 17 March 2020; Published 25 April 2020

Academic Editor: Xesús Nogueira

Copyright (c) 2020 Trung Thanh Tran et al. This is an open access article distributed under the Creative Commons Attribution License, which permits unrestricted use, distribution, and reproduction in any medium, provided the original work is properly cited.

\begin{abstract}
In this paper, free vibration analysis of the functionally graded porous (FGP) plates on the elastic foundation taking into mass (EFTIM) is presented. The fundamental equations of the FGP plate are derived using Hamilton's principle. The mixed interpolation of the tensorial components (MITC) approach and the edge-based smoothed finite element method (ES-FEM) is employed to avoid the shear locking as well as to improve the accuracy for the triangular element. The EFTIM is a foundation model based on the two-parameter Winkler-Pasternak model but added a mass parameter of foundation. Materials of the plate are FGP with a power-law distribution and maximum porosity distributions in the forms of cosine functions. Some numerical examples are examined to demonstrate the accuracy and reliability of the proposed method in comparison with those available in the literature.
\end{abstract}

\section{Introduction}

The plate resting on the elastic foundation (EF) is one of the most common types of structures which have practical applications in civil and industrial constructions, especially in transportation and irrigation. In particular, the structures of beams and plates on the EF are subjected to moving loads of means of transport such as roadbeds affected by vehicles, railway tracks, and aircraft runways. In most publications, when investigating the mechanical behavior of structures on the $\mathrm{EF}$, the researchers mainly use the one-parameter Winkler foundation model [1] or two-parameter Winkler-Pasternak foundation model $[2,3]$. The analysis of plates resting on the Winkler-Pasternak foundation was previously addressed by several authors. For instance, Fazzolari [3] used an analytical method to consider free vibration and buckling of porous FG Sandwich beams resting on the EF with the Winkler-Pasternak foundation model. Leissa [4] presented results for the free vibration of rectangular plates. Xiang et al. [5] studied free vibration for Mindlin plates on the Winkler-Pasternak foundation using an analytical method. Omurtag et al. [6] used the finite element method (FEM) for the free vibration analysis of the Kirchhoff plates resting on the EF. Özçelikörs et al. [7] analyzed the exact solutions of bending, buckling, and vibration problems of a Levy-plate on the two-parameter foundation. Matsunaga [8] used a special higher-order plate theory (HSDT) to analyze vibration and buckling of thick plates on the EF. Ayvaz et al. [9] developed a modified Vlasov model to consider the earthquake response of thin plates on the EF. Shen et al. [10] based on the Rayleigh-Ritz method to study free and forced vibration of the Reissner-Mindlin plates resting on the EF. Liew et al. $[11,12]$ and Han and Liew [13] analyzed the free vibration of rectangular 
plates resting on the EF using a differential quadrature method. Zhou et al. [14] considered the vibration of rectangular plates on the EF using the Ritz method. Chucheepsakul and Chinnaboon [15] investigated plates by a two-parameter foundation model using a boundary element method. Civalek and Acar [16] investigated the bending of Mindlin plates on the EF by developing a singular convolution method. Ferreira et al. [17] presented bending and free vibration analyses of the FGP plates on the Winkler-Pasternak foundation by using radial basis functions. Shahsavari et al. [18] used a new quasi-3D hyperbolic theory for the free vibration analysis of the FGP plates resting on the EF. Zenkour and Radwan [19] proposed an exact analytical approach for free vibration analysis of laminated composite and Sandwich plates resting on the EF using a four-unknown plate theory. Duc et al. [20] presented the analysis of nonlinear thermal dynamic response of shear deformable functionally graded plates on the EF. Mahmoudi et al. [21] developed a refined quasi-three-dimensional shear deformation theory to analyze the functionally graded Sandwich plates resting on the two-parameter EF under thermomechanical loading. Duc et al. [22] used an analytical method to calculate static bending and free vibration of FG carbon nanotube-reinforced composite plate resting on Winkler-Pasternak foundations. Thang et al. [23] considered the effects of variable thickness on buckling and postbuckling behavior of imperfect sigmoid FGM plates on elastic medium subjected to compressive loading. BanhThien et al. [24] developed the isogeometric analysis for buckling analysis of nonuniform thickness nanoplates in an elastic medium.

In recent years, the FGP materials have attracted great interest from many researchers over the world due to their lightness and high strength. As a result, they are widely applied for civil engineering, aerospace structures, nuclear plants, and other applications. Kim et al. [25] investigated bending, vibration, and buckling of the FGP microplates using a modified couples stress based on the analytical method. Coskun et al. [26] presented analytical solutions to analyze the bending, vibration, and buckling of the FG microplates based on the third-order shear deformation theory (TSDT). Chen et al. [27] investigated the static bending and buckling of the FGP beams by using the Timoshenko beam theory. Rezaei and Saidi $[28,29]$ studied the vibration of rectangular and porous-cellular plates based on an analytical method. The vibration of the FGP shallow shells using an improve Fourier method was examined by Zhao et al. [30]. Moreover, the dynamics of the FGP doubly-curved panels and shells were also investigated in [31]. Li et al. [32] analyzed the nonlinear vibration and dynamic buckling of the Sandwich FGP plates with graphene platelet reinforcement (GPL) on the EF. For nonlinear problems, Sahmani et al. [33] used the nonlocal method to analyze nonlinear large-amplitude vibrations of the FGP micro-/nanoplates with GPL reinforce. Wu et al. [34] studied the dynamic of the FGP structures by using FEM. Thang et al. [35] investigated the elastic buckling and free vibration of porous cellular plates based on the first-order shear deformation theory (FSDT). Although the FGP materials have many different types, in this paper, the authors only use the distribution of porosity as presented in $[25,26]$.

In the other front of the development of numerical methods for computational mechanics, Liu et al. [36] have recently proposed an edge-based smoothed FEM (ES-FEM) using triangular elements which show some following excellent properties for the 2D solid mechanics analyses such as (1) the numerical results are often found superconvergent and very accurate; (2) the method is stable and works well for dynamic analysis; and (3) the implementation of the method is straightforward and no penalty parameter is used. The ES-FEM has been developed for n-sided polygonal elements [37], viscoelastoplastic analyses [38], 2D piezoelectric [39], primal-dual shakedown analyses [40], fluid structure interaction $[41,42]$, and various applications [43-45]. Recently, in an effort to improve the accuracy of the plate and shell structural analyses, the classical MITC3 element [46] incorporated with the ES-FEM [36], has been proposed to give the so-called ES-MITC3 element [47-51]. In the formulation of the ES-MITC3, the system stiffness matrix is employed using strains smoothed over the smoothing domains associated with the edges of the MITC3 elements. The numerical results demonstrated that the ESMITC3 has the following great properties [47]: (1) the ES-MITC3 can eliminate transverse shear locking even with the ratio of the thickness to the length of the structures reach $10^{-8}$ and (2) the ES-MITC3 has better accuracy than the existing triangular elements such as MITC3 [46], DSG3 [52], and CS-DSG3 [53] and is a good competitor with the quadrilateral element MITC4 element [54].

The objective of this research now is to further extend the ES-MITC3 method for free vibration analyses of the FGP plates resting on the EFTIM. The governing equations are derived from the FSDT and the Reissner-Mindlin plate theory due to simplicity and computational efficiency. Besides, the EFTIM is modelled based on a two-parameter Winkler-Pasternak foundation model and added in a mass parameter of foundation. The plate is made from the FGP materials with a power-law distribution $(k)$ and maximum porosity distributions $(\Omega)$ in the forms of cosine functions. The accuracy and reliability of the present formulation are verified by comparing with those of other available numerical results. Moreover, the effects of some geometric parameters and material properties on the free vibration of the FGP plates are also examined in detail.

\section{Functionally Graded Porous Material Plates on Elastic Foundation}

Let us consider an FGP plate resting on EFTIM, as shown in Figure 1. The FGP materials with a variation of two 
constituents and three different distributions of porosity through-thickness are presented as follows $[25,26]$ :

$$
\begin{aligned}
& \text { Case 1: } \Lambda(z)=\Omega \cos \left(\frac{\pi z}{h}\right), \\
& \text { Case 2: } \Lambda(z)=\Omega \cos \left[\frac{\pi}{2}\left(\frac{z}{h}+0.5\right)\right], \\
& \text { Case 3: } \Lambda(z)=\Omega \cos \left[\frac{\pi}{2}\left(\frac{z}{h}-0.5\right)\right],
\end{aligned}
$$

where $\Omega$ is the maximum porosity value. A typical material property of the FGP materials can be considered as in the following power-law relations:

$$
P(z)=\left[\left(P_{t}-P_{b}\right)\left(\frac{z}{h}+0.5\right)^{k}+P_{b}\right](1-\Lambda(z)),
$$

where $P_{t}$ and $P_{b}$ are the typical material properties at the top and the bottom surfaces, respectively; and $k$ is the power-law index. The normalized distributions of porosity through the thickness are shown in Figure 2(a). As shown in Figure 2(a), the porosity distribution of Case 1 is symmetric with respect to the midplane of plates. Case 2 and Case 3 are bottom and top surface-enhanced distributions, respectively. Besides, Figures 2(b)-2(d) show the distributions of a normalized typical property associated with three different cases of porosity distributions with parameters: $\Omega=0.5, k=1,5,10$, and $P_{t} / P_{b}=10$.

The EFTIM is built based on the Winkler-Pasternak foundation by adding a mass parameter of foundation:

$$
\mathbf{q}_{e}=k_{1} w(x, y, t)-k_{2}\left(\frac{\partial^{2}}{\partial x^{2}}+\frac{\partial^{2}}{\partial y^{2}}\right) w(x, y, t)+m_{f} \frac{\partial^{2} w(x, y, t)}{\partial t^{2}},
$$

where $w$ is the displacement of FGP plate; $k_{1}$ and $k_{2}$ are, respectively, Winkler foundation stiffness and shear layer stiffness of the Pasternak foundation. In order to mention the effectiveness of the foundation mass involved in the oscillation as well as the continuous interaction of the spring with the plate, the parameter $\beta$ with unit $\mathrm{kg}^{-1}$ is added. It characterizes the effective level of the foundation mass involved in vibration, which is determined based on an experimental basis and the ratio of the density of the foundation to the density of plate material which is defined as $\boldsymbol{\mu}_{F}=\rho_{F} / \rho$. Thus, the density of mass $m_{\mathrm{f}}$ involved vibration with the foundation is determined $m_{f}=\beta \mu_{F} \rho$. From equation (3) we see that, for the static problem, the EFTIM model and Winkler-Pasternak foundation model are the same. But, for the dynamic problems, these two models have differences, and when omitting the influence parameters of the foundation mass, the EFTIM model is equivalent to the Winkler-Pasternak foundation model. In addition, this foundation model also covers the Winkler foundation model when the influence of shear parameters and foundation mass parameters ignored. It was found that the EFTIM model

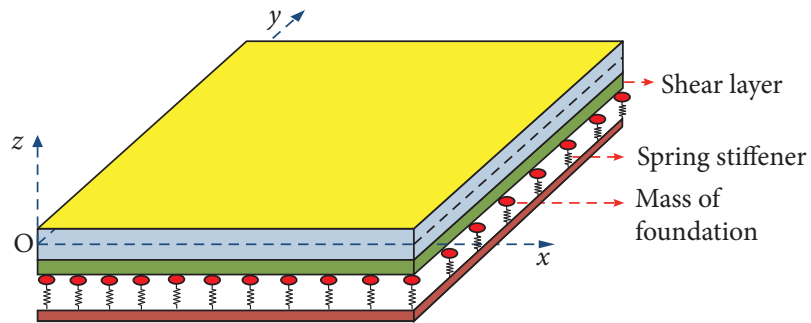

FIGURE 1: Modeling the FGP plate resting on EFTIM.

closely resembles the true feature of the foundation, including the Pasternak and Winkler foundation models.

\section{The First-Order Shear Deformation Theory and Weak Form of the FGP Plates}

3.1. First-Order Shear Deformation Theory for FGP Plates. The displacement of the FGP plates in the present work based on the FSDT model can be expressed as

$$
\left\{\begin{array}{l}
u(x, y, z)=u_{0}(x, y)+z \theta_{x}(x, y), \\
v(x, y, z)=v_{0}(x, y)+z \theta_{y}(x, y), \\
w(x, y, z)=w_{0}(x, y),
\end{array}\right.
$$

where $u, v, w, \theta_{x}$, and $\theta_{y}$ are five unknown displacements of the midsurface of the plate. For a bending plate, the strain field can be expressed as follows:

$$
\boldsymbol{\varepsilon}=\boldsymbol{\varepsilon}_{m}+z \boldsymbol{\kappa}
$$

where the membrane strain is given as

$$
\boldsymbol{\varepsilon}_{m}=\left\{\begin{array}{c}
u_{0, x} \\
v_{0, y} \\
u_{0, y}+v_{0, x}
\end{array}\right\} .
$$

The bending and transverse shear strains are written as

$$
\begin{aligned}
& \boldsymbol{\kappa}=\left\{\begin{array}{c}
\theta_{x, x} \\
\theta_{y, y} \\
\theta_{x, y}+\theta_{y, x}
\end{array}\right\}, \\
& \boldsymbol{\gamma}=\left\{\begin{array}{c}
w_{0, x}+\theta_{x} \\
w_{0, y}+\theta_{y}
\end{array}\right\} .
\end{aligned}
$$

From Hooke's law, the linear stress-strain relations of the FGP plates can be expressed as

$$
\left\{\begin{array}{c}
\sigma_{x} \\
\sigma_{y} \\
\tau_{x y} \\
\tau_{x z} \\
\tau_{y z}
\end{array}\right\}=\left[\begin{array}{ccccc}
Q_{11} & Q_{12} & 0 & 0 & 0 \\
Q_{21} & Q_{22} & 0 & 0 & 0 \\
0 & 0 & Q_{66} & 0 & 0 \\
0 & 0 & 0 & Q_{55} & 0 \\
0 & 0 & 0 & 0 & Q_{44}
\end{array}\right]\left\{\begin{array}{c}
\varepsilon_{x} \\
\varepsilon_{y} \\
\gamma_{x y} \\
\gamma_{x z} \\
\gamma_{y z}
\end{array}\right\},
$$




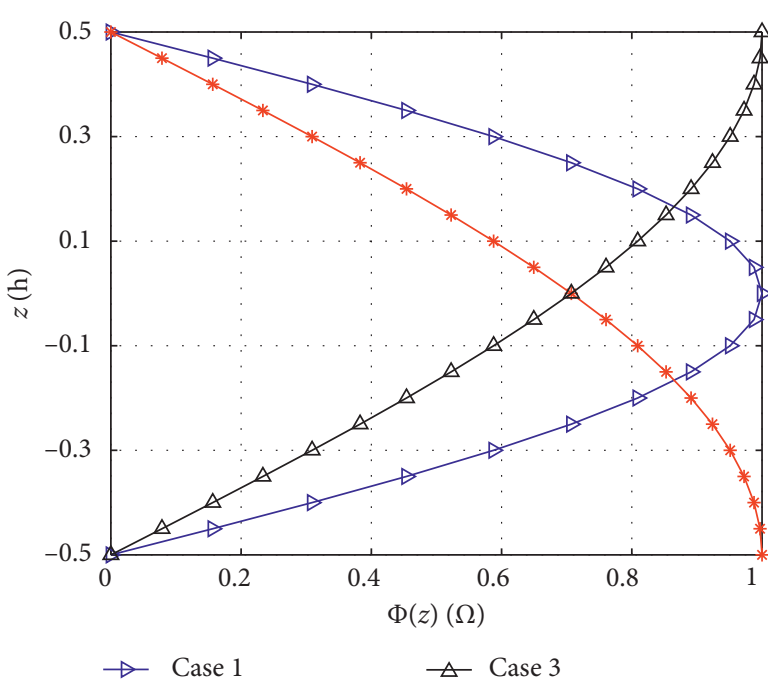

(a)

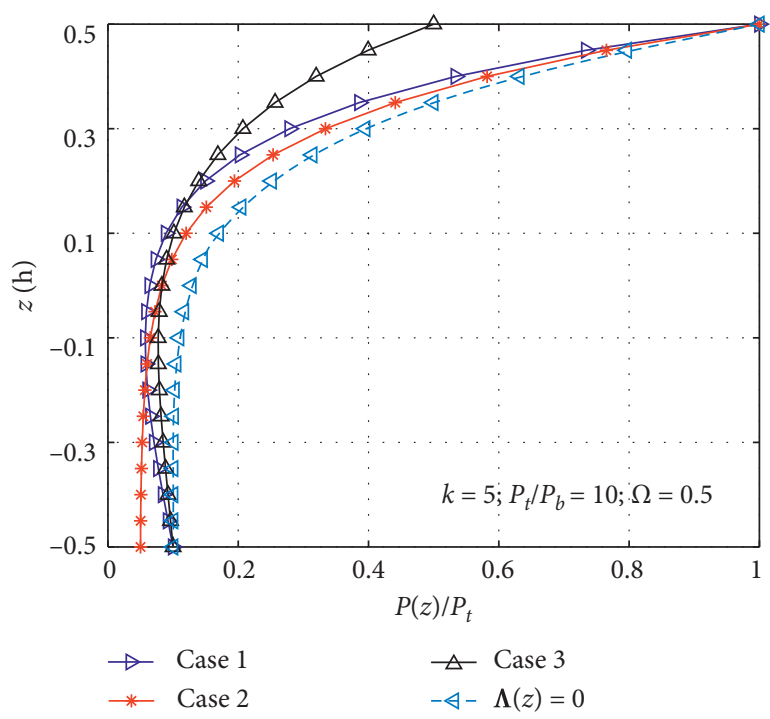

(c)

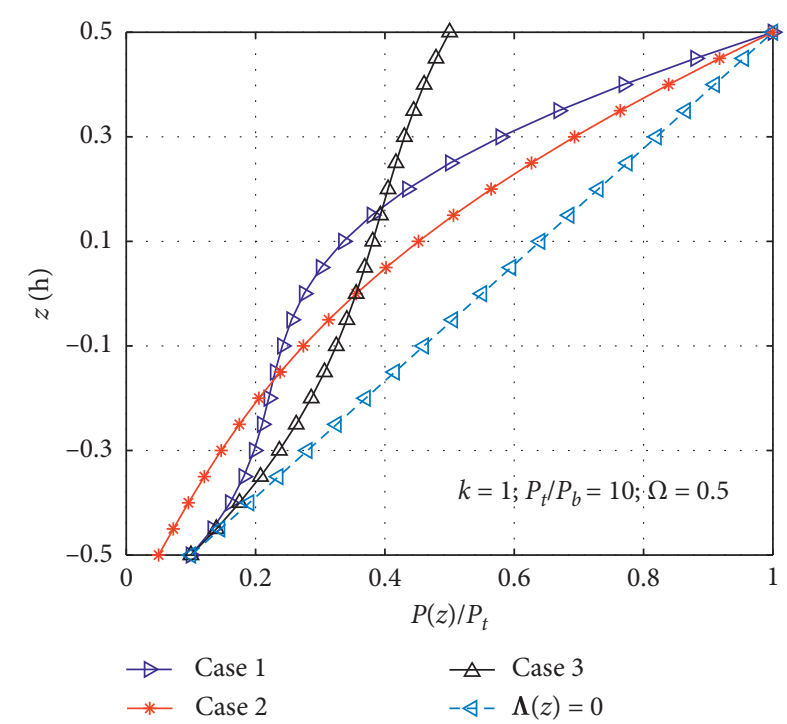

(b)

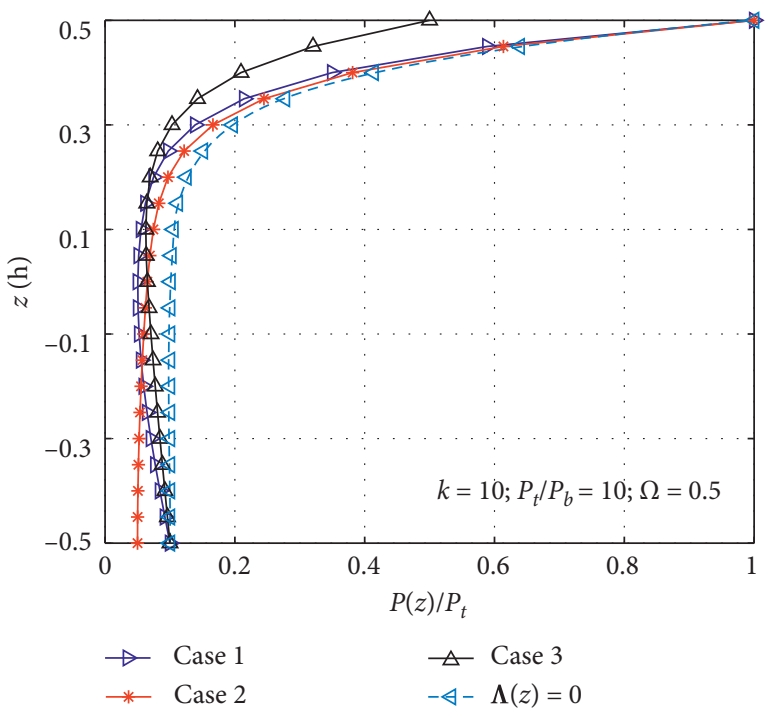

(d)

FIGURE 2: Distributions of porosity and typical material property. (a) Distribution of porosity along of $z$-axis, (b) distribution material property with $k=1$, (c) distribution material property with $k=5$, and (d) distribution material property with $k=10$.

where

$$
\begin{aligned}
& Q_{11}=Q_{22}=\frac{E(z)}{1-v^{2}}, \\
& Q_{12}=Q_{21}=\frac{v E(z)}{1-v^{2}}, \\
& Q_{44}=Q_{55}=Q_{66}=\frac{E(z)}{2(1+v)} .
\end{aligned}
$$

where $E(z)$ presents for effective Young's modulus and $v$ represents Poisson's ratio.

3.2. Weak Form Equations. To obtain the motion equations of the FGP plates for the free vibration analysis, Hamilton's principle is applied with the following form:

$$
\int_{t_{1}}^{t_{2}}(\delta \mathscr{U}-\delta \mathscr{K}) \mathrm{d} t=0,
$$

where $\mathcal{U}$ and $\mathscr{K}$ are the strain and kinetic energies, respectively. The strain energy is expressed as

$$
\mathcal{U}=\mathcal{U}^{p}+\mathscr{U}^{f}
$$

where $\mathcal{U}^{f}$ is the strain energy

$$
\mathcal{U}^{f}=\frac{1}{2} \int_{\psi}\left(k_{1} w^{2}-k_{2}\left[\left(\frac{\partial^{2} w}{\partial x^{2}}\right)^{2}+\left(\frac{\partial^{2} w}{\partial y^{2}}\right)^{2}\right]\right) \mathrm{d} \psi
$$

and $\mathcal{U}^{p}$ is the strain energy

$$
\mathcal{U}^{p}=\frac{1}{2} \int_{\psi}\left(\boldsymbol{\varepsilon}^{T} \mathbf{D} \boldsymbol{\varepsilon}+\boldsymbol{\gamma}^{T} \mathbf{C} \boldsymbol{\gamma}\right) \mathrm{d} \psi .
$$


where $\boldsymbol{\varepsilon}=\left[\begin{array}{ll}\boldsymbol{\varepsilon}_{m} & \boldsymbol{\kappa}\end{array}\right]^{T}$ and

$$
\mathbf{D}=\left[\begin{array}{ll}
\mathbf{A} & \mathbf{B} \\
\mathbf{B} & \mathbf{F}
\end{array}\right]
$$

and $\mathbf{A}, \mathbf{B}, \mathbf{F}$, and $\mathbf{C}$ can be given by

$$
\begin{aligned}
(\mathbf{A}, \mathbf{B}, \mathbf{F}) & =\int_{-h / 2}^{h / 2}\left(1, z, z^{2}\right)\left[\begin{array}{ccc}
Q_{11} & Q_{12} & 0 \\
Q_{21} & Q_{22} & 0 \\
0 & 0 & Q_{66}
\end{array}\right] \mathrm{d} z, \\
\mathbf{C} & =\int_{-h / 2}^{h / 2}\left[\begin{array}{cc}
Q_{55} & 0 \\
0 & Q_{44}
\end{array}\right] \mathrm{d} z .
\end{aligned}
$$

The kinetic energy in equation (11) is given by

$$
\mathscr{K}=\mathscr{K}^{p}+\mathscr{K}^{f},
$$

where $\mathscr{K}^{p}$ is the kinetic energy

$$
\mathscr{K}^{p}=\frac{1}{2} \int_{\psi} \dot{\mathbf{u}} \mathbf{m}_{\mathrm{p}} \mathbf{u} \mathrm{d} \psi,
$$

where $\mathbf{u}^{T}=\left[\begin{array}{lllllll}u_{0} & v_{0} & w_{0} & \theta_{x} & \theta_{y} & \phi_{x} & \phi_{y}\end{array}\right]$ is the displacement field and $\mathbf{m}_{\mathrm{p}}$ is the mass matrix defined by

$$
\mathbf{m}_{\mathrm{p}}=\left[\begin{array}{ccccc}
I_{1} & 0 & 0 & I_{2} & 0 \\
& I_{1} & 0 & 0 & I_{2} \\
& & I_{1} & 0 & 0 \\
& & & I_{3} & 0 \\
& & & & I_{3}
\end{array}\right],
$$

where $\left(I_{1}, I_{2}, I_{3}\right)=\int_{-h / 2}^{h / 2} \rho\left(1, z, z^{2}\right) \mathrm{d} z$.

In equation (11), the kinetic energy of the mass of foundation $\mathscr{K}^{f}$ is defined as

$$
\mathscr{K}^{f}=\frac{1}{2} \int_{\psi} \dot{\mathbf{w}} \mathbf{m}_{\mathrm{f}} \mathbf{w} \mathrm{d} \psi .
$$

Substituting equations (12) and (18) into equation (11), the weak formulation for the free vibration of the FGP plate is finally obtained as

$$
\begin{aligned}
& \int_{\psi} \delta \boldsymbol{\varepsilon}^{T} \mathbf{D} \boldsymbol{\varepsilon} \mathrm{d} \psi+\int_{\psi} \delta \gamma^{T} \mathbf{C} \boldsymbol{\gamma} \psi+\int_{\psi} \delta \mathbf{w}^{T} \\
& \cdot\left[k_{1} w-k_{2}\left(\frac{\partial^{2} w}{\partial x^{2}}+\frac{\partial^{2} w}{\partial y^{2}}\right)\right] \mathrm{d} \psi=\int_{\psi} \dot{\mathbf{u}} \mathbf{m}_{\mathrm{p}} \mathbf{u} \mathrm{d} \psi \\
& \quad+\int_{\psi} \dot{\mathbf{w}} \mathbf{m}_{\mathrm{f}} \mathbf{w} \mathrm{d} \psi .
\end{aligned}
$$

\section{Formulation of an ES-MITC3 Method for FGP Plates}

4.1. Formulation of the Finite Element Using the MITC3 Element. The middle surface of plate $\psi$ is discretized into $n^{e}$ finite three-node triangular elements with $n^{n}$ nodes such that $\psi \approx \sum_{e=1}^{n^{e}} \psi_{e}$ and $\psi_{i} \cap \psi_{j}=\varnothing, i \neq j$. Then, the generalized displacements at any point $\mathbf{u}^{e}=\left[u_{j}^{e}, v_{j}^{e}, w_{j}^{e}, \theta_{x j}^{e}, \theta_{y j}^{e}\right]^{T}$ of element $\psi_{e}$ can be approximated as

$$
\begin{aligned}
\mathbf{u}^{e}(\mathbf{x}) & =\sum_{j=1}^{n^{n e}}\left[\begin{array}{ccccc}
N_{I}(\mathrm{x}) & 0 & 0 & 0 & 0 \\
0 & N_{I}(\mathrm{x}) & 0 & 0 & 0 \\
0 & 0 & N_{I}(\mathrm{x}) & 0 & 0 \\
0 & 0 & 0 & N_{I}(\mathrm{x}) & 0 \\
0 & 0 & 0 & 0 & N_{I}(\mathrm{x})
\end{array}\right] \mathbf{d}_{j}^{e} \\
& =\sum_{j=1}^{n^{n e}} \mathbf{N}(\mathbf{x}) \mathbf{d}_{j}^{e},
\end{aligned}
$$

where $n^{n e}$ is the number of nodes of $\psi_{e} ; \mathbf{N}(\mathbf{x})$ is the shape function matrix; and $\mathbf{d}_{j}^{e}=\left[u_{j}^{e}, v_{j}^{e}, w_{j}^{e}, \theta_{x j}^{e}, \theta_{y j}^{e}\right]^{T}$ is the nodal degrees of freedom (d.o.f) associated with the $j^{\text {th }}$ node of $\psi_{e}$.

The membrane bending strains of MITC3 element can be expressed in matrix forms as follows:

$$
\begin{aligned}
\boldsymbol{\varepsilon}_{m}^{e} & =\left[\begin{array}{lll}
\mathbf{B}_{m 1}^{e} & \mathbf{B}_{m 2}^{e} & \mathbf{B}_{m 3}^{e}
\end{array}\right] \mathbf{d}^{e}=\mathbf{B}_{m}^{e} \mathbf{d}^{e}, \\
\boldsymbol{\kappa}^{e} & =\left[\begin{array}{lll}
\mathbf{B}_{b 1}^{e} & \mathbf{B}_{b 2}^{e} & \mathbf{B}_{b 3}^{e}
\end{array}\right] \mathbf{d}^{e}=\mathbf{B}_{b}^{e} \mathbf{d}^{e},
\end{aligned}
$$

where

$$
\begin{aligned}
\mathbf{B}_{m 1}^{e} & =\frac{1}{2 A_{e}}\left[\begin{array}{ccccc}
b-c & 0 & 0 & 0 & 0 \\
0 & d-a & 0 & 0 & 0 \\
d-a & b-c & 0 & 0 & 0
\end{array}\right], \\
\mathbf{B}_{m 2}^{e} & =\frac{1}{2 A_{e}}\left[\begin{array}{ccccc}
c & 0 & 0 & 0 & 0 \\
0 & -d & 0 & 0 & 0 \\
-d & c & 0 & 0 & 0
\end{array}\right],
\end{aligned}
$$

$$
\mathbf{B}_{m 3}^{e}=\frac{1}{2 A_{e}}\left[\begin{array}{ccccc}
-b & 0 & 0 & 0 & 0 \\
0 & a & 0 & 0 & 0 \\
a & -b & 0 & 0 & 0
\end{array}\right],
$$

$$
\mathbf{B}_{b 1}^{e}=\frac{1}{2 A_{e}}\left[\begin{array}{ccccc}
0 & 0 & 0 & b-c & 0 \\
0 & 0 & 0 & 0 & d-a \\
0 & 0 & 0 & d-a & b-c
\end{array}\right],
$$

$$
\mathbf{B}_{b 2}^{e}=\frac{1}{2 A_{e}}\left[\begin{array}{ccccc}
0 & 0 & 0 & c & 0 \\
0 & 0 & 0 & 0 & -d \\
0 & 0 & 0 & -d & c
\end{array}\right],
$$

$$
\mathbf{B}_{b 3}^{e}=\frac{1}{2 A_{e}}\left[\begin{array}{ccccc}
0 & 0 & 0 & -b & 0 \\
0 & 0 & 0 & 0 & a \\
0 & 0 & 0 & a & -b
\end{array}\right],
$$

To eliminate the shear locking phenomenon as the thickness of the plate becomes small, the formulation of the transverse shear strains of the MITC3 element based on FSDT [36] in this study can be written as follows:

$$
\gamma^{e}=\mathbf{B}_{s}^{e} \mathbf{d}^{e},
$$

where 


$$
\mathbf{B}_{s}^{e}=\left[\begin{array}{lll}
\mathbf{B}_{s 1}^{e} & \mathbf{B}_{s 2}^{e} & \mathbf{B}_{s 3}^{e}
\end{array}\right]
$$

with

$$
\begin{aligned}
& \mathbf{B}_{s 1}^{e}=\mathbf{J}^{-1}\left[\begin{array}{cccccc}
0 & 0 & -1 & \frac{a}{3}+\frac{d}{6} & \frac{b}{3}+\frac{c}{6} \\
0 & 0 & -1 & \frac{d}{3}+\frac{a}{6} & \frac{c}{3}+\frac{b}{6}
\end{array}\right], \\
& \mathbf{B}_{s 2}^{e}=\mathbf{J}^{-1}\left[\begin{array}{ccccc}
0 & 0 & 1 & \frac{a}{2}-\frac{d}{6} & \frac{b}{2}-\frac{c}{6} \\
0 & 0 & 0 & \frac{d}{6} & \frac{c}{6}
\end{array}\right], \\
& \mathbf{B}_{s 3}^{e(0)}=\mathbf{J}^{-1}\left[\begin{array}{ccccc}
0 & 0 & 0 & \frac{a}{6} & \frac{b}{6} \\
0 & 0 & 1 & \frac{d}{2}-\frac{a}{6} & \frac{c}{2}-\frac{b}{6}
\end{array}\right],
\end{aligned}
$$

where

$$
\mathbf{J}^{-1}=\frac{1}{2 A_{e}}\left[\begin{array}{cc}
c & -b \\
-d & a
\end{array}\right]
$$

Here, $a=x_{2}-x_{1}, b=y_{2}-y_{1}, c=y_{3}-y_{1}$, and $d=x_{3}-$ $x_{1}$ are pointed out in and $A_{e}$ is the area of the three-node triangular element as shown in Figure 3.

Substituting the discrete displacement field into equation (22), we obtained the discrete system equations for free vibration analysis of FGP plate resting on the EF, respectively, as

$$
\left(\mathbf{K}-\omega^{2} \mathbf{M}\right) \mathbf{d}=0
$$

where $\mathbf{K}$ and $\mathbf{M}$ are the stiffness and mass matrices, respectively.

The stiffness matrix in equation (38) can be written as

$$
\mathbf{K}=\sum_{e=1}^{n^{e}}\left(\mathbf{K}_{p}^{e}+\mathbf{K}_{f}^{e}\right),
$$

where

$$
\begin{aligned}
\mathbf{K}_{p}^{e}= & \int_{\psi_{e}} \mathbf{B}^{T} \mathbf{D B} \mathrm{d} \psi_{e}+\int_{\psi_{e}} \mathbf{B}_{s}^{T} \mathbf{C B}_{s} \mathrm{~d} \psi_{e}, \\
\mathbf{K}_{f}^{e}= & k_{1} \int_{\psi_{e}} \mathbf{N}_{w}^{\mathrm{T}} \mathbf{N}_{w} \mathrm{~d} \psi_{e}+k_{2} \int_{\psi_{e}}\left[\left(\frac{\partial \mathbf{N}_{w}}{\partial x}\right)^{\mathrm{T}}\left(\frac{\partial \mathbf{N}_{w}}{\partial x}\right)\right. \\
& \left.+\left(\frac{\partial \mathbf{N}_{w}}{\partial y}\right)^{\mathrm{T}}\left(\frac{\partial \mathbf{N}_{w}}{\partial y}\right)\right] \mathrm{d} \psi_{e},
\end{aligned}
$$

where

$$
\begin{aligned}
& \mathbf{B}^{e}=\left[\begin{array}{ll}
\mathbf{B}_{m}^{e} & \mathbf{B}_{b}^{e}
\end{array}\right]
\end{aligned}
$$

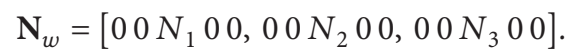

Next, the mass matrix in equation (38) can be defined as

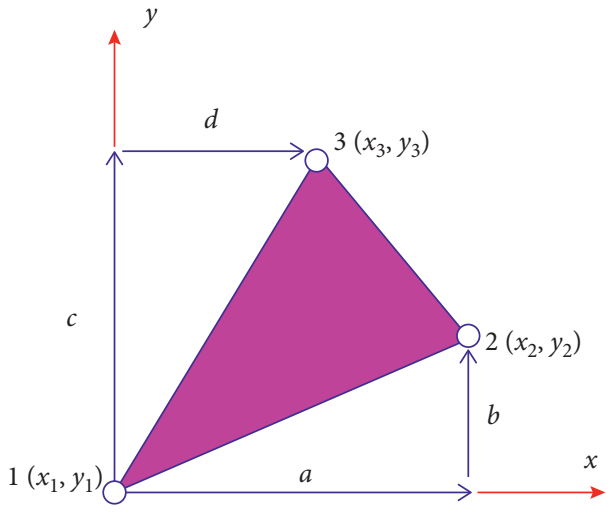

FIgURE 3: Three-node triangular element in the local coordinates.

$$
\mathbf{M}=\sum_{e=1}^{n^{e}}\left(\mathbf{M}_{p}^{e}+\mathbf{M}_{f}^{e}\right)
$$

where

$$
\begin{aligned}
\mathbf{M}_{p}^{e} & =\int_{\psi_{e}} \mathbf{N}^{T} \mathbf{m}_{\mathrm{p}} \mathbf{N} \mathrm{d} \psi_{e}, \\
\mathbf{M}_{f}^{e} & =\mathbf{m}_{\mathrm{f}} \int_{\psi_{e}} \mathbf{N}_{w}^{T} \mathbf{N}_{w} \mathrm{~d} \psi_{e} .
\end{aligned}
$$

4.2. Formulation of an ES-MITC3 Method for FGP Plates. The smoothing domains $\psi^{k}$ is constructed based on edges of the triangular elements such that $\psi=\cup_{k=1}^{n^{k}} \psi^{k}$ and $\psi_{i}^{k} \cap \psi_{j}^{k}=\varnothing$ for $i \neq j$. An edge-based smoothing domain $\psi^{k}$ for the inner edge $k$ is formed by connecting two end-nodes of the edge to the centroids of adjacent triangular MITC3 elements, as shown in Figure 4.

Applying the edge-based smooth technique [36], the smoothed membrane, bending, and shear strain $\widetilde{\boldsymbol{\varepsilon}}_{m}^{k}, \widetilde{\mathbf{\kappa}}^{k}, \widetilde{\boldsymbol{\gamma}}^{k}$ over the smoothing domain $\psi^{k}$ can be created by

$$
\begin{aligned}
& \widetilde{\boldsymbol{\varepsilon}}_{m}^{k}=\int_{\psi^{k}} \boldsymbol{\varepsilon}_{m} \Phi^{k}(\mathbf{x}) \mathrm{d} \psi, \\
& \widetilde{\mathbf{k}}^{k}=\int_{\psi^{k}} \boldsymbol{\kappa} \Phi^{k}(\mathbf{x}) \mathrm{d} \psi, \\
& \widetilde{\boldsymbol{\gamma}}^{k}=\int_{\psi^{k}} \gamma \Phi^{k}(\mathbf{x}) \mathrm{d} \psi,
\end{aligned}
$$

where $\boldsymbol{\varepsilon}_{m}, \boldsymbol{\kappa}$, and $\boldsymbol{\gamma}$ the compatible membrane, bending, and the shear strains, respectively; $\Phi^{k}(\mathbf{x})$ is a given smoothing function that satisfies at least unity property $\int_{\psi^{k}} \Phi^{k}(\mathbf{x}) \mathrm{d} \psi=1$.

In this study, we use the constant smoothing function

$$
\Phi^{k}(\mathbf{x})= \begin{cases}\frac{1}{A^{k}}, & x \in \psi^{k}, \\ 0, & x \notin \psi^{k},\end{cases}
$$




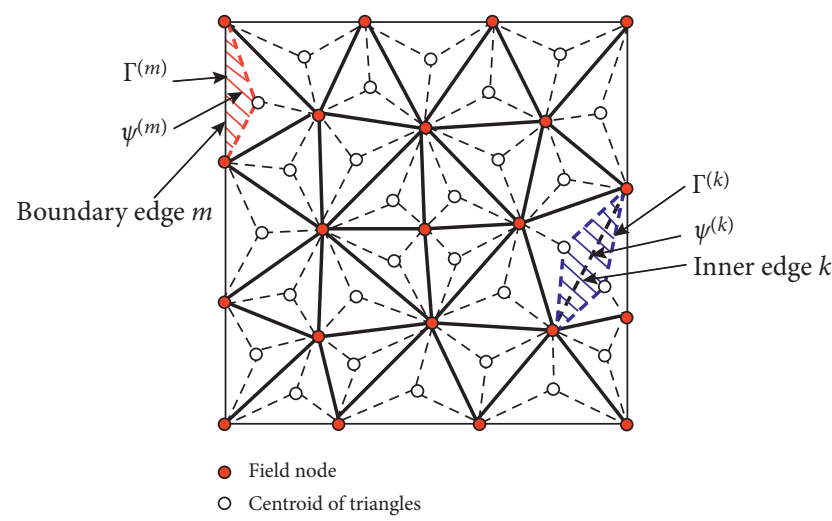

Figure 4: The smoothing domain $\psi^{k}$ is formed by triangular elements.

where $A^{k}$ is the area of the smoothing domain $\psi^{k}$ and is given by

$$
A^{k}=\int_{\psi^{k}} \mathrm{~d} \psi=\frac{1}{3} \sum_{i=1}^{n^{e k}} A^{i},
$$

where $n^{e k}$ is the number of the adjacent triangular elements in the smoothing domain $\psi^{k}$; and $A^{i}$ is the area of the $i$ th triangular element attached to the edge $k$.

By substituting equations (47)-(49) into equations (24), (25), and (32), the approximation of the smoothed strains on the smoothing domain $\psi^{k}$ can be expressed as follows:

$$
\begin{aligned}
\widetilde{\boldsymbol{\varepsilon}}_{m}^{k} & =\sum_{j=1}^{n^{n k}} \widetilde{\mathbf{B}}_{m j}^{k} \mathbf{d}_{j}^{k} ; \\
\widetilde{\mathbf{k}}^{k} & =\sum_{j=1}^{n_{s h}^{n k}} \widetilde{\mathbf{B}}_{b j}^{k} \mathbf{d}_{j}^{k} ; \\
\boldsymbol{\gamma}^{k} & =\sum_{j=1}^{n_{s h}^{n k}} \widetilde{\mathbf{B}}_{s j}^{k} \mathbf{d}_{j}^{k} ;
\end{aligned}
$$

where $n_{s h}^{n k}$ is the total number of nodes of the triangular MITC3 elements attached to edge $k\left(n_{s h}^{n k}=3\right.$ for boundary edges and $n_{s h}^{n k}=4$ for inner edges as given in Figure $4 ; \mathbf{d}_{j}^{k}$ is the nodal d.o.f associated with the smoothing domain $\psi^{k}$; and $\widetilde{\mathbf{B}}_{m j}^{k}, \widetilde{\mathbf{B}}_{b j}^{k}$, and $\widetilde{\mathbf{B}}_{s j}^{k}$ are the smoothed membrane, bending, and shear strain gradient matrices, respectively, at the $j^{\text {th }}$ node of the elements attached to edge $k$ computed by

$$
\begin{gathered}
\widetilde{\mathbf{B}}_{m j}^{k}=\frac{1}{A^{k}} \sum_{i=1}^{n^{e k}} \frac{1}{3} A^{i} \mathbf{B}_{m j}^{e}, \\
\widetilde{B}_{b j}^{k}=\frac{1}{A^{k}} \sum_{i=1}^{n^{e k}} \frac{1}{3} A_{i} \mathbf{B}_{\mathrm{bj}}^{e}, \\
\widetilde{B}_{\mathrm{sj}}^{k}=\frac{1}{A^{k}} \sum_{i=1}^{n^{e k}} \frac{1}{3} A^{i} \mathbf{B}_{\mathrm{sj}}^{e} .
\end{gathered}
$$

The stiffness matrix of the FGP plate using the ESMITC3 is assembled by

$$
\widetilde{\mathbf{K}}=\sum_{\mathrm{k}=1}^{n_{\mathrm{sh}}^{k}} \widetilde{\mathbf{K}}^{k},
$$

where $\widetilde{\mathbf{K}}^{k}$ is the ES-MITC3 stiffness matrix of the smoothing domain $\psi^{k}$ and given by

$$
\widetilde{\mathbf{K}}^{k}=\int_{\psi^{k}}\left(\widetilde{\mathbf{B}}^{\mathrm{KT}} \mathbf{D} \widetilde{\mathbf{B}}^{k}+\widetilde{\mathbf{B}}_{s}^{k t} \mathbf{C} \widetilde{\mathbf{B}}_{s}^{k}\right) \mathrm{d} \psi=\widetilde{\mathbf{B}}^{\mathrm{KT}} \mathbf{D} \widetilde{\mathbf{B}}^{k} A^{k}+\widetilde{\mathbf{B}}_{s}^{k t} \widetilde{\mathbf{C B}}_{s}^{k} A^{k},
$$

where

$$
\widetilde{\mathbf{B}}^{k T}=\left[\begin{array}{cc}
\widetilde{\mathbf{B}}_{\mathrm{mj}}^{k} & \widetilde{\mathbf{B}}_{\mathrm{bj}}^{k}
\end{array}\right]
$$

\section{Accuracy of the Proposed Method}

In this section, the various numerical examples are solved to verify the reliability and accuracy of the proposed method. For convenience, the stiffness factors and nondimensional frequencies of the plates are defined as the following equations:

$$
\begin{aligned}
K_{1} & =\frac{k_{1} a^{4}}{H} ; \\
K_{2} & =\frac{k_{2} a^{2}}{H} ; \\
\lambda & =\frac{\omega a^{2}}{\pi^{2}} \sqrt{\frac{\rho h}{H}}, \quad \text { with } H=\frac{E h^{3}}{12\left(1-v^{2}\right)} .
\end{aligned}
$$

To demonstrate the performance of numerical results, the relative frequency error is defined by

$$
\Delta(\%)=100 \times \frac{\left|\lambda_{p r}-\lambda_{r e}\right|}{\left|\lambda_{r e}\right|},
$$

where $\lambda_{p r}$ and $\lambda_{r e}$ are nondimensional frequencies of present method and nondimensional frequencies in $[17,18]$, respectively.

The results of the convergence of the first two nondimensional frequencies of the plate in the case of fully simple support (SSSS) plate and a fully clamped (CCCC) plate with $h / a=0.1, K_{1}=100, K_{2}=10$, respectively, are shown in Figure 5. From these results, it can be seen that almost all frequencies corresponding to different cases of boundary conditions $(\mathrm{BC})$ converge with $18 \times 18$ element mesh. For $18 \times 18$ mesh, we compare the first three nondimensional frequencies of a plate resting on the Winkler-Pasternak foundation with the published results as shown in Table 1. It can be seen that the present results agree well with the results of the authors using analytical methods $[5,14,17]$ and are more accurate than those using the original MITC3 element and FEM [6]. In addition, from Table 2, it is obvious that the relative error of the present results compared to [18] is less than $2 \%$. In [18], they used a new quasi-3D hyperbolic theory to investigate the free vibration of the FGP plate resting on the EF. These results are the basis to analyze the free vibration of FGP plates on the EFTIM. 


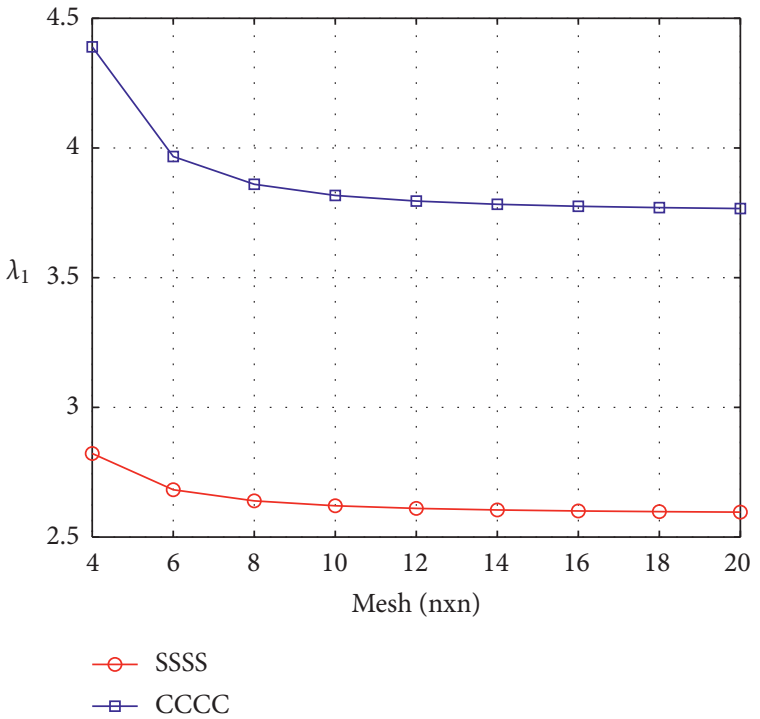

(a)

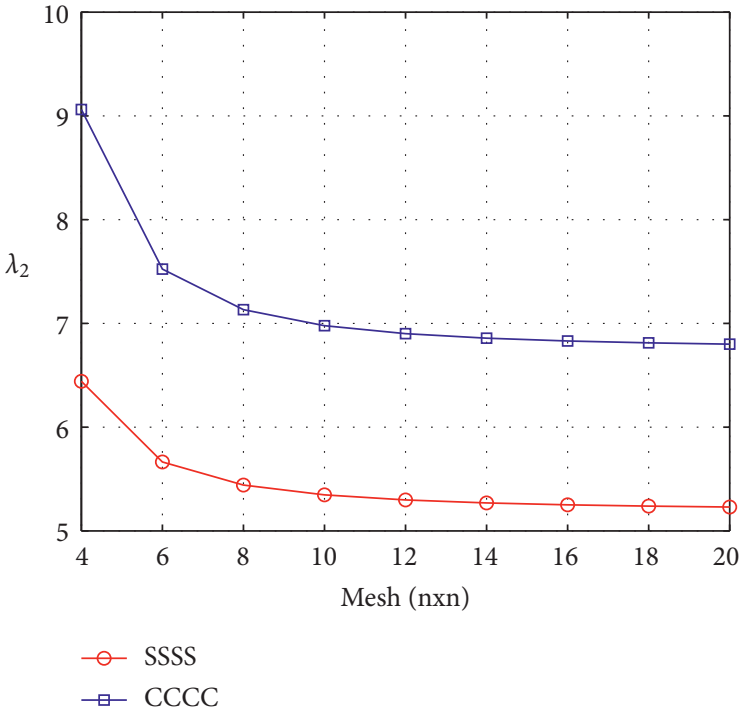

(b)

Figure 5: The convergence of element mesh to nondimensional frequency of plate. (a) $\lambda_{1}$ and (b) $\lambda_{2}$.

TABle 1: Nondimensional frequencies of plates.

\begin{tabular}{|c|c|c|c|c|c|c|c|c|c|}
\hline Plates & $K_{1}$ & $K_{2}$ & Author & $\lambda_{1}$ & $\Delta(\%)$ & $\lambda_{2}$ & $\Delta(\%)$ & $\lambda_{3}$ & $\Delta(\%)$ \\
\hline \multirow{10}{*}{$\begin{array}{l}\text { SSSS } \\
v=0.3 \\
h / a=0.01\end{array}$} & \multirow{5}{*}{100} & \multirow{5}{*}{10} & Ferreira et al. [17] & 2.6559 & & 5.5718 & & 8.5384 & \\
\hline & & & Zhou et al. [14] & 2.6551 & 0.03 & 5.5717 & 0.00 & 8.5406 & 0.03 \\
\hline & & & Xiang et al. [5] & 2.6551 & 0.03 & 5.5718 & 0.00 & 8.5405 & 0.02 \\
\hline & & & MITC3 & 2.6604 & 0.17 & 5.6103 & 0.70 & 8.6296 & 1.07 \\
\hline & & & Present & 2.6590 & 0.12 & 5.5920 & 0.37 & 8.6017 & 0.74 \\
\hline & \multirow{5}{*}{500} & \multirow{5}{*}{10} & Ferreira [17] & 3.3406 & & 5.9285 & & 8.7754 & \\
\hline & & & Zhou et al. [14] & 3.3398 & 0.02 & 5.9285 & 0.00 & 8.7775 & 0.02 \\
\hline & & & Xiang et al. [5] & 3.3400 & 0.02 & 5.9287 & 0.00 & 8.7775 & 0.02 \\
\hline & & & MITC3 & 3.3441 & 0.10 & 5.9649 & 0.61 & 8.8642 & 1.01 \\
\hline & & & Present & 3.3430 & 0.07 & 5.9477 & 0.32 & 8.8370 & 0.70 \\
\hline \multirow{10}{*}{$\begin{array}{l}\text { SSSS } \\
v=0.3 \\
h / a=0.1\end{array}$} & \multirow{5}{*}{200} & \multirow{5}{*}{10} & Ferreira et al. [17] & 2.7902 & & 5.3452 & & 7.8255 & \\
\hline & & & Zhou et al. [14] & 2.7756 & 0.52 & 5.2954 & 0.93 & 7.7279 & 1.25 \\
\hline & & & Xiang et al. [5] & 2.7842 & 0.22 & 5.3043 & 0.77 & 7.7287 & 1.24 \\
\hline & & & MITC3 & 2.7874 & 0.10 & 5.3258 & 0.36 & 7.7719 & 0.68 \\
\hline & & & Present & 2.7887 & 0.05 & 5.3362 & 0.17 & 7.7971 & 0.36 \\
\hline & \multirow{5}{*}{1000} & \multirow{5}{*}{10} & Ferreira et al. [17] & 3.9844 & & 6.0430 & & 8.3112 & \\
\hline & & & Zhou et al. [14] & 3.9566 & 0.70 & 5.9757 & 1.11 & 8.1954 & 1.39 \\
\hline & & & Xiang et al. [5] & 3.9805 & 0.10 & 6.0078 & 0.58 & 8.2214 & 1.08 \\
\hline & & & MITC3 & 3.9827 & 0.04 & 6.0266 & 0.27 & 8.2619 & 0.59 \\
\hline & & & Present & 3.9836 & 0.02 & 6.0358 & 0.12 & 8.2856 & 0.31 \\
\hline \multirow{5}{*}{$\begin{array}{l}\text { CCCC } \\
v=0.15 \\
h / a=0.015\end{array}$} & \multirow{5}{*}{1390.2} & \multirow{5}{*}{166.83} & Ferreira et al. [17] & 8.1669 & & 12.821 & & 16.842 & \\
\hline & & & Zhou et al. [14] & 8.1675 & 0.01 & 12.823 & 0.02 & 16.833 & 0.05 \\
\hline & & & Omurtag et al. [6] & 8.1375 & 0.36 & 12.898 & 0.60 & 16.932 & 0.53 \\
\hline & & & MITC3 & 8.1842 & 0.21 & 12.909 & 0.69 & 17.010 & 1.00 \\
\hline & & & Present & 8.1729 & 0.07 & 12.872 & 0.40 & 16.939 & 0.58 \\
\hline
\end{tabular}

Next, we consider an SSSS FGP plate $\left(\mathrm{Al} / \mathrm{Al}_{2} \mathrm{O}_{3}\right)$ with its material properties as follows: metal (Al) $E_{b}=70 \mathrm{GPa}, \rho_{b}=2702 \mathrm{~kg} / \mathrm{m}^{3}$ and ceramic $\left(\mathrm{Al}_{2} \mathrm{O}_{3}\right)$ $E_{t}=380 \mathrm{GPa}, \rho_{t}=3800 \mathrm{~kg} / \mathrm{m}^{3}$. Poisson's ratio is fixed at $v=0.3$. The FGP plate with even porosities is expressed as in $[18]$ :

$$
P(z)=P_{b}+\left(P_{t}-P_{b}\right)\left(\frac{z}{h}+0.5\right)^{k}-\frac{\xi}{2}\left(P_{t}+P_{b}\right),
$$

where $\xi(\xi \leq 1)$ presents the porosity volume fraction. The stiffness factor and nondimensional frequencies of the plates are shown in equation (58) with $H_{b}=\left(E_{b} h^{3} / 12\left(1-v^{2}\right)\right)$ and 
TABLE 2: The first nondimensional frequencies of FGP plate according to the Winkler-Pasternak foundation stiffness $(k=1)$.

\begin{tabular}{|c|c|c|c|c|c|c|c|}
\hline \multirow{2}{*}{$\left(K_{1}, K_{2}\right)$} & \multirow{2}{*}{$h / a$} & \multicolumn{3}{|c|}{$\xi=0$} & \multicolumn{3}{|c|}{$\xi=0.2$} \\
\hline & & Present & {$[18]$} & $\Delta(\%)$ & Present & [18] & $\Delta(\%)$ \\
\hline \multirow{4}{*}{$(0,0)$} & 0.05 & 9.010 & 9.020 & 0.11 & 8.485 & 8.370 & 1.37 \\
\hline & 0.10 & 8.823 & 8.818 & 0.06 & 8.319 & 8.203 & 1.41 \\
\hline & 0.15 & 8.541 & 8.516 & 0.29 & 8.069 & 7.950 & 1.50 \\
\hline & 0.20 & 8.196 & 8.151 & 0.55 & 7.762 & 7.641 & 1.58 \\
\hline \multirow{4}{*}{$(100,0)$} & 0.05 & 9.389 & 9.430 & 0.43 & 9.020 & 8.917 & 1.16 \\
\hline & 0.10 & 9.207 & 9.231 & 0.26 & 8.858 & 8.753 & 1.20 \\
\hline & 0.15 & 8.933 & 8.934 & 0.01 & 8.614 & 8.505 & 1.28 \\
\hline & 0.20 & 8.599 & 8.577 & 0.26 & 8.315 & 8.203 & 1.37 \\
\hline \multirow{4}{*}{$(100,100)$} & 0.05 & 15.383 & 15.439 & 0.36 & 16.338 & 16.320 & 0.11 \\
\hline & 0.10 & 15.213 & 15.245 & 0.21 & 16.175 & 16.148 & 0.17 \\
\hline & 0.15 & 14.962 & 14.966 & 0.03 & 15.932 & 15.895 & 0.23 \\
\hline & 0.20 & 14.664 & 14.640 & 0.16 & 15.639 & 15.595 & 0.28 \\
\hline
\end{tabular}

TABLe 3: Nondimensional frequencies of the FGP plate on EFTIM.

\begin{tabular}{lccccc}
\hline$\lambda_{1}$ & $\lambda_{2}$ & $\lambda_{3}$ & $\lambda_{4}$ & $\lambda_{5}$ & $\lambda_{6}$ \\
\hline 0.8583 & 1.8118 & 1.8157 & 2.8015 & 3.3898 & 3.4248 \\
\hline
\end{tabular}

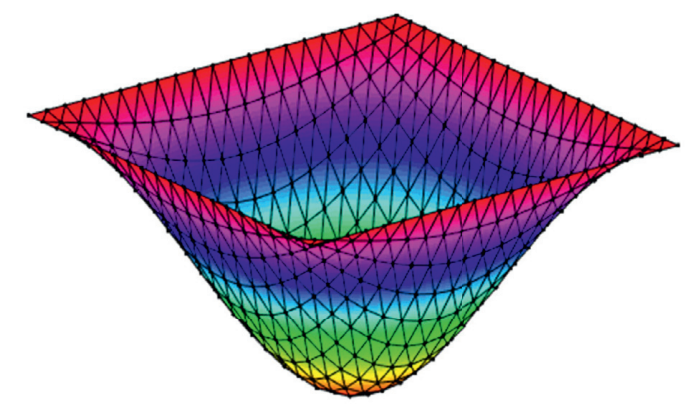

(a)

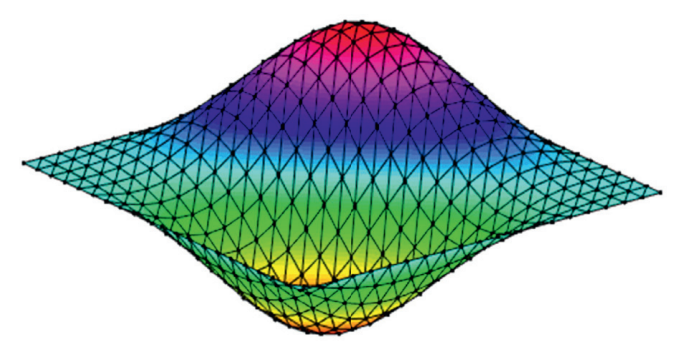

(c)

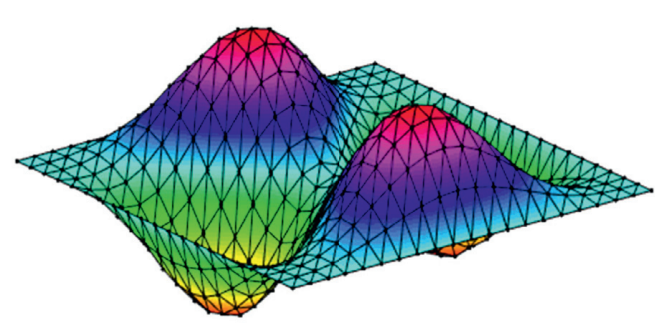

(e)

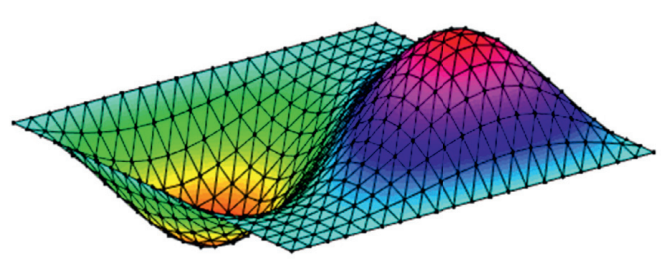

(b)

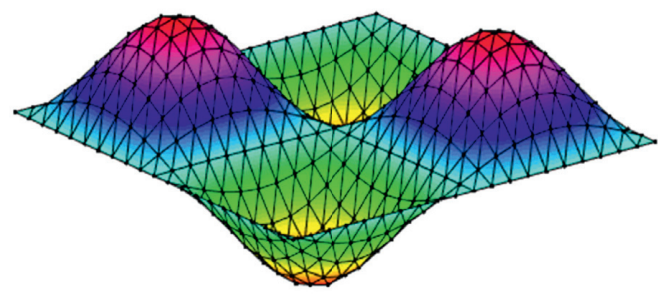

(d)

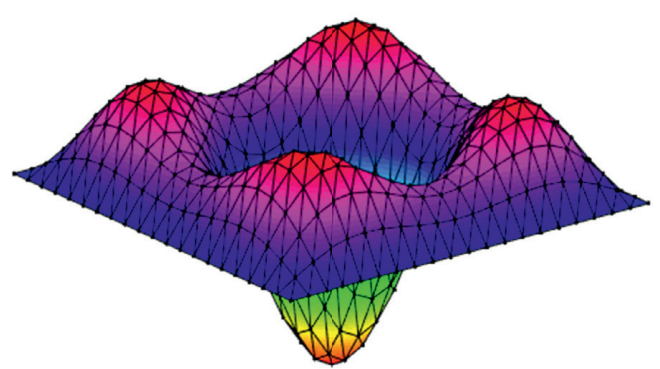

(f)

FIgUre 6: The first six mode sharps the FGP plate on EFTIM. 


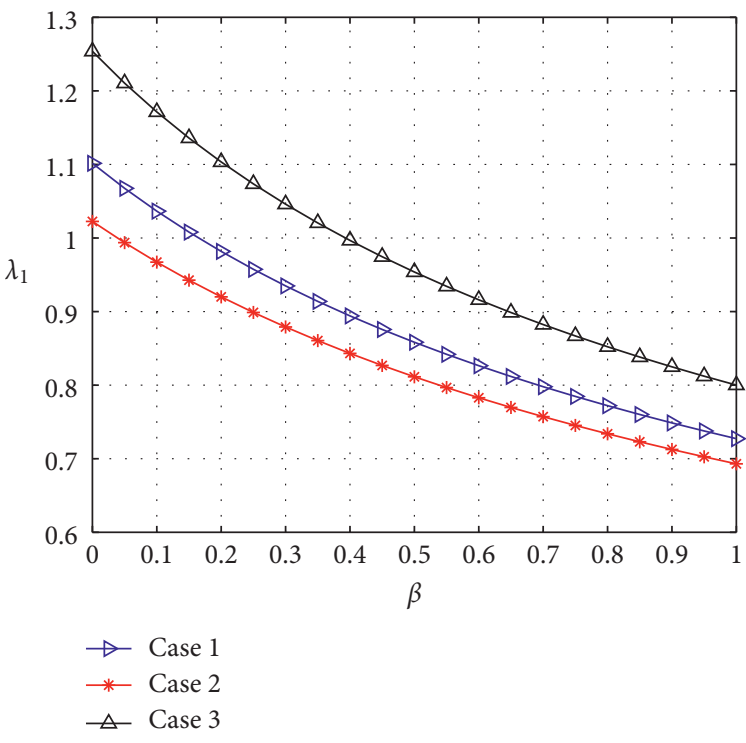

(a)

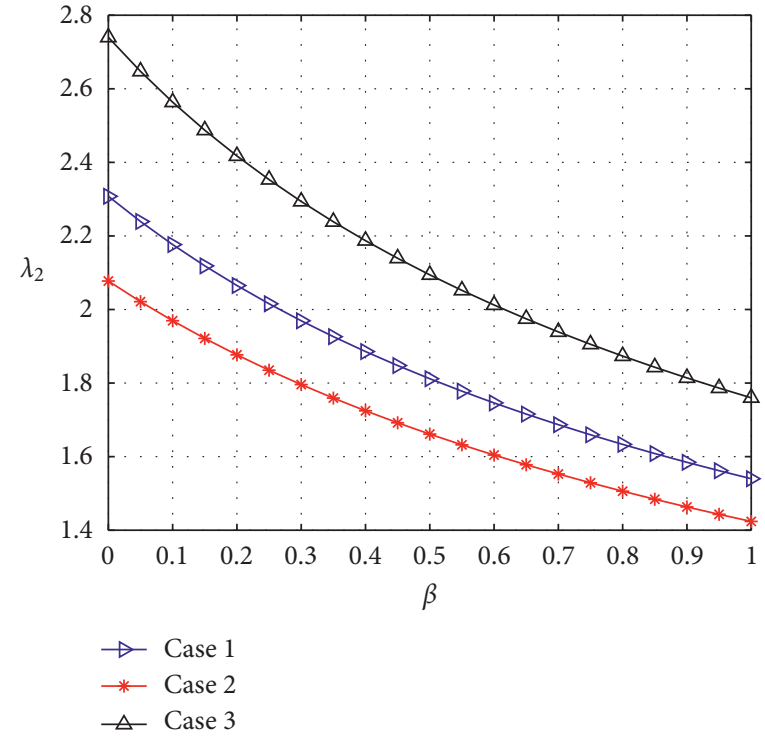

(b)

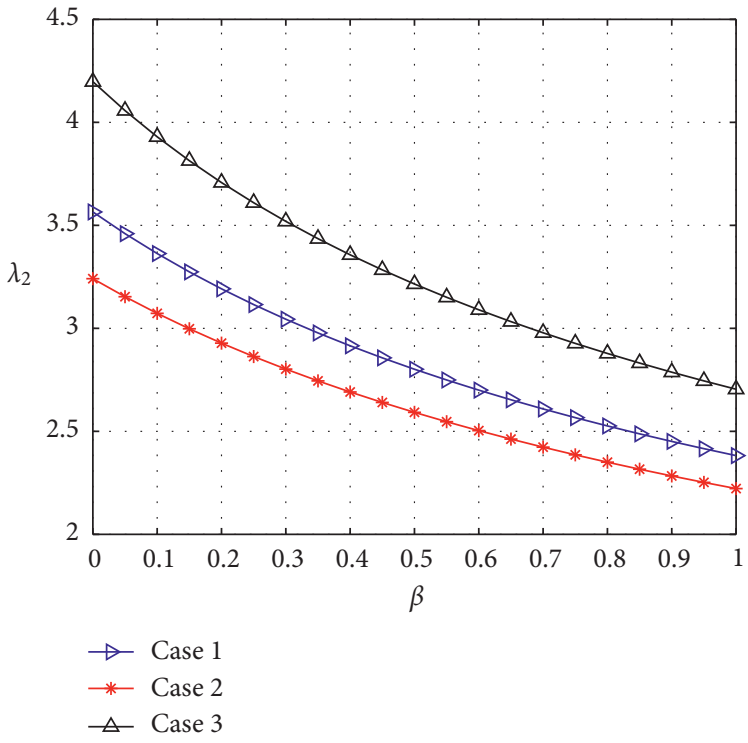

(c)

Figure 7: Nondimensional frequencies of the eFGP plate with difference of featured-index $\beta$ : (a) nondimensional frequency $\lambda_{1}$; (b) nondimensional frequency $\lambda_{2}$; and (c) nondimensional frequency $\lambda_{3}$.

TABLE 4: The first three nondimensional frequencies of FGP on EFTIM.

\begin{tabular}{|c|c|c|c|c|c|c|}
\hline Parameter of plate & $\beta$ & 0 & 0.25 & 0.5 & 0.75 & 1 \\
\hline Case 1 & $\lambda_{1}$ & 1.1015 & 0.9575 & 0.8583 & 0.7847 & 0.7273 \\
\hline$\left(K_{1}=100, K_{2}=10\right)$ & $\lambda_{2}$ & 2.3078 & 2.0156 & 1.8118 & 1.6595 & 1.5400 \\
\hline (SSSS) & $\lambda_{3}$ & 3.5651 & 3.1154 & 2.8015 & 2.5665 & 2.3822 \\
\hline Case 2 & $\lambda_{1}^{3}$ & 1.0225 & 0.8988 & 0.8113 & 0.7453 & 0.6931 \\
\hline$\left(K_{1}=100, K_{2}=10\right)$ & $\lambda_{2}$ & 2.0774 & 1.8350 & 1.6612 & 1.5289 & 1.4239 \\
\hline (SSSS) & $\lambda_{3}$ & 3.2410 & 2.8630 & 2.5921 & 2.3859 & 2.2221 \\
\hline Case 3 & $\lambda_{1}$ & 1.2537 & 1.0735 & 0.9538 & 0.8669 & 0.8001 \\
\hline$\left(K_{1}=100, K_{2}=10\right)$ & $\lambda_{2}$ & 2.7399 & 2.3531 & 2.0942 & 1.9054 & 1.7599 \\
\hline (SSSS) & $\lambda_{3}$ & 4.1972 & 3.6097 & 3.2152 & 2.9269 & 2.7044 \\
\hline
\end{tabular}


TABLE 5: Nondimensional frequencies of the FGP plate with different $K_{1}$ and $K_{2}$.

\begin{tabular}{|c|c|c|c|c|c|c|}
\hline \multirow{2}{*}{ Case of Porosity distribution } & \multirow{2}{*}{$K_{2}$} & \multicolumn{5}{|c|}{$K_{1}$} \\
\hline & & 100 & 250 & 500 & 750 & 1000 \\
\hline \multirow{5}{*}{$\begin{array}{l}\text { Case } 1 \\
\text { (SSSS) }\end{array}$} & 10 & 0.8583 & 0.8929 & 0.9477 & 0.9995 & 1.0488 \\
\hline & 25 & 0.9258 & 0.9579 & 1.0092 & 1.0580 & 1.1047 \\
\hline & 50 & 1.0285 & 1.0575 & 1.1042 & 1.1490 & 1.1921 \\
\hline & 75 & 1.1218 & 1.1485 & 1.1916 & 1.2332 & 1.2734 \\
\hline & 100 & 1.2079 & 1.2327 & 1.2730 & 1.3120 & 1.3499 \\
\hline \multirow{5}{*}{$\begin{array}{l}\text { Case } 2 \\
\text { (SSSS) }\end{array}$} & 10 & 0.8113 & 0.8452 & 0.8988 & 0.9493 & 0.9973 \\
\hline & 25 & 0.8775 & 0.9089 & 0.9589 & 1.0064 & 1.0518 \\
\hline & 50 & 0.9778 & 1.0061 & 1.0515 & 1.0950 & 1.1369 \\
\hline & 75 & 1.0687 & 1.0947 & 1.1365 & 1.1769 & 1.2160 \\
\hline & 100 & 1.1525 & 1.1765 & 1.2156 & 1.2534 & 1.2902 \\
\hline \multirow{5}{*}{$\begin{array}{l}\text { Case } 3 \\
\text { (SSSS) }\end{array}$} & 10 & 0.9538 & 1.0009 & 1.0747 & 1.1438 & 1.2090 \\
\hline & 25 & 1.0452 & 1.0883 & 1.1566 & 1.2211 & 1.2823 \\
\hline & 50 & 1.1819 & 1.2202 & 1.2815 & 1.3400 & 1.3960 \\
\hline & 75 & 1.3044 & 1.3392 & 1.3953 & 1.4492 & 1.5011 \\
\hline & 100 & 1.4163 & 1.4484 & 1.5004 & 1.5507 & 1.5993 \\
\hline
\end{tabular}

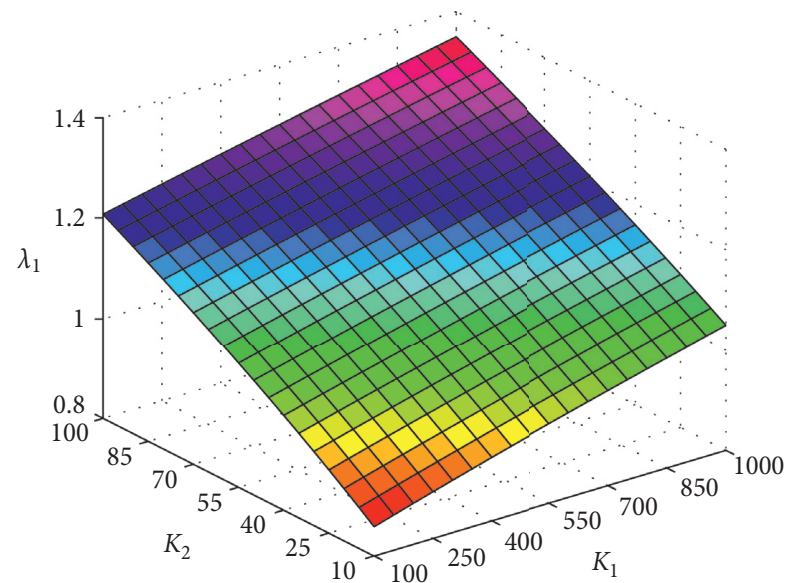

(a)

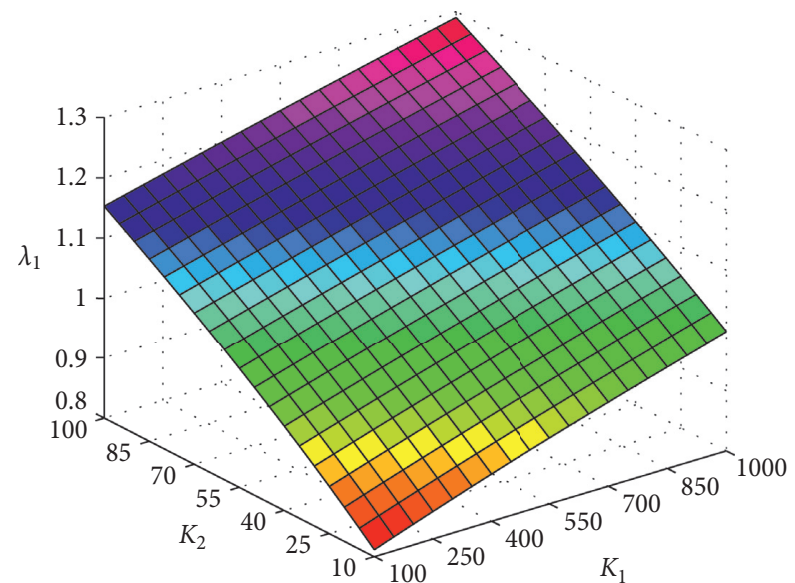

(b)

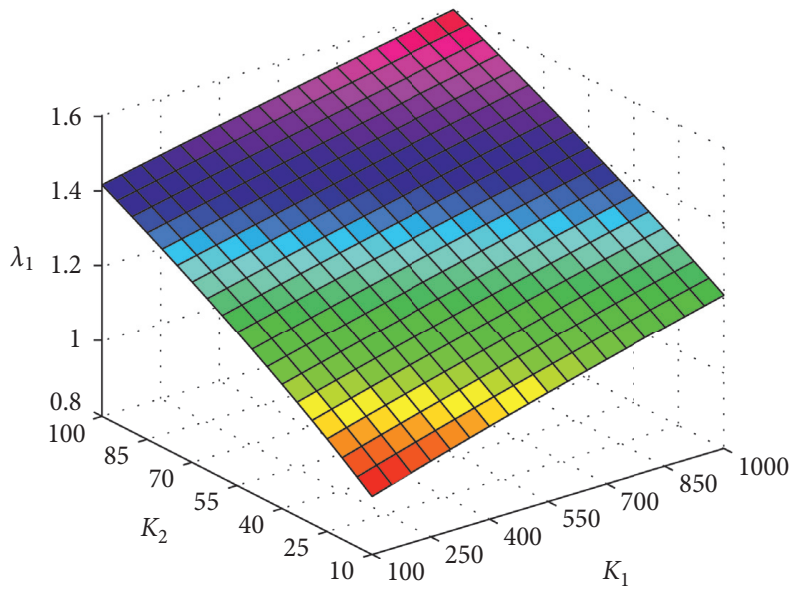

(c)

Figure 8: Nondimensional frequencies of FGP plate with different $K_{1}$ and $K_{2}$. (a) Case 1; (b) Case 2; and (c) Case 3. 
TABLE 6: Nondimensional frequencies of FGP plate with different $K_{1}, K_{2}$, and $\beta$.

\begin{tabular}{|c|c|c|c|c|c|c|c|c|c|c|}
\hline \multirow{2}{*}{$\begin{array}{l}\beta \\
\text { Case }\end{array}$} & \multicolumn{5}{|c|}{$K_{1}\left(K_{2}=10\right)$} & \multicolumn{5}{|c|}{$K_{2}\left(K_{1}=100\right)$} \\
\hline & & & & & & & & & & \\
\hline & 100 & 250 & 500 & 750 & 1000 & 10 & 25 & 50 & 75 & 100 \\
\hline 0 & 1.1015 & 1.1459 & 1.2163 & 1.2828 & 1.3460 & 1.1015 & 1.1882 & 1.3199 & 1.4397 & 1.5502 \\
\hline 0.25 & 0.9575 & 0.9961 & 1.0572 & 1.1150 & 1.1700 & 0.9575 & 1.0328 & 1.1473 & 1.2514 & 1.3475 \\
\hline 0.5 & 0.8583 & 0.8929 & 0.9477 & 0.9995 & 1.0488 & 0.8583 & 0.9258 & 1.0285 & 1.1218 & 1.2079 \\
\hline 0.75 & 0.7847 & 0.8163 & 0.8664 & 0.9138 & 0.9588 & 0.7847 & 0.8464 & 0.9403 & 1.0256 & 1.1043 \\
\hline 1 & 0.7273 & 0.7566 & 0.8030 & 0.8469 & 0.8887 & 0.7273 & 0.7844 & 0.8715 & 0.9505 & 1.0235 \\
\hline \multicolumn{11}{|c|}{ Case 2} \\
\hline 0 & 1.0225 & 1.0652 & 1.1327 & 1.1964 & 1.2569 & 1.0225 & 1.1059 & 1.2323 & 1.3469 & 1.4525 \\
\hline 0.25 & 0.8988 & 0.9363 & 0.9957 & 1.0517 & 1.1049 & 0.8988 & 0.9721 & 1.0833 & 1.1840 & 1.2768 \\
\hline 0.5 & 0.8113 & 0.8452 & 0.8988 & 0.9493 & 0.9973 & 0.8113 & 0.8775 & 0.9778 & 1.0687 & 1.1525 \\
\hline 0.75 & 0.7453 & 0.7763 & 0.8256 & 0.8720 & 0.9161 & 0.7453 & 0.8060 & 0.8982 & 0.9817 & 1.0586 \\
\hline 1 & 0.6931 & 0.7220 & 0.7677 & 0.8109 & 0.8519 & 0.6931 & 0.7496 & 0.8353 & 0.9129 & 0.9845 \\
\hline \multicolumn{11}{|c|}{ Case 3} \\
\hline 0 & 1.2537 & 1.3156 & 1.4127 & 1.5035 & 1.5891 & 1.2537 & 1.3739 & 1.5536 & 1.7146 & 1.8617 \\
\hline 0.25 & 1.0735 & 1.1265 & 1.2096 & 1.2874 & 1.3607 & 1.0735 & 1.1764 & 1.3303 & 1.4681 & 1.5941 \\
\hline 0.5 & 0.9538 & 1.0009 & 1.0747 & 1.1438 & 1.2090 & 0.9538 & 1.0452 & 1.1819 & 1.3044 & 1.4163 \\
\hline 0.75 & 0.8669 & 0.9097 & 0.9768 & 1.0396 & 1.0988 & 0.8669 & 0.9500 & 1.0742 & 1.1855 & 1.2872 \\
\hline 1 & 0.8001 & 0.8395 & 0.9015 & 0.9595 & 1.0141 & 0.8001 & 0.8767 & 0.9914 & 1.0942 & 1.1880 \\
\hline
\end{tabular}
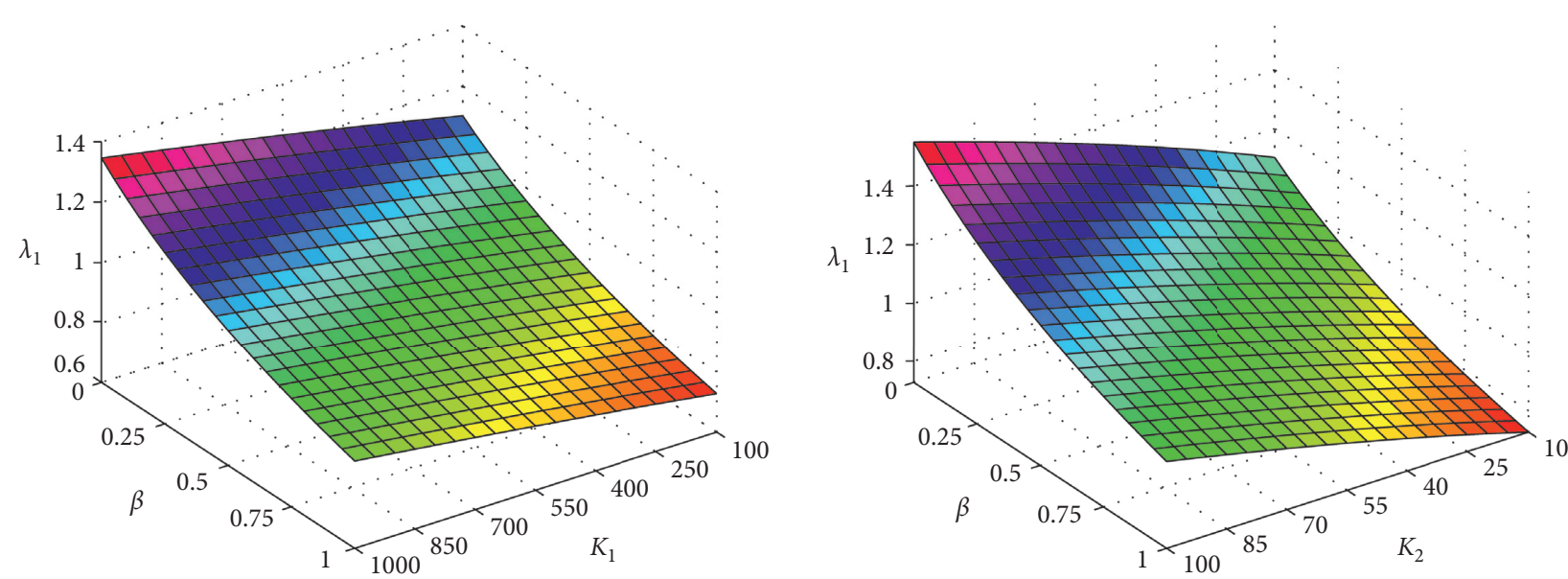

(a)
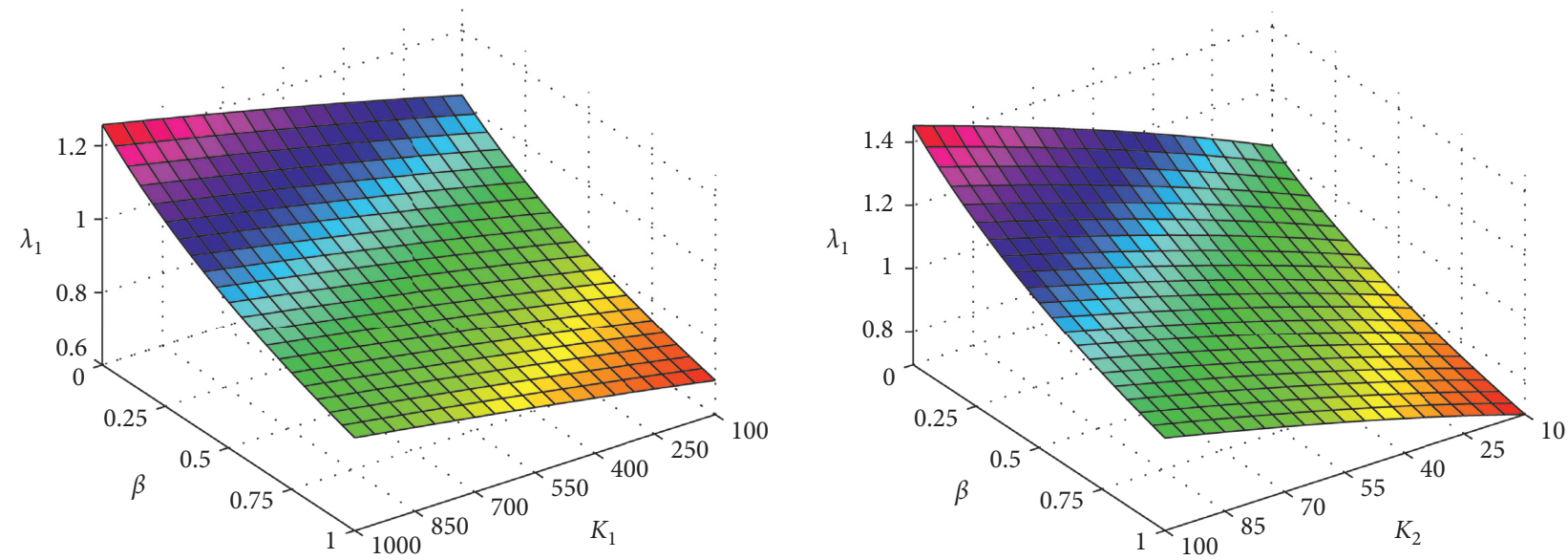

(b)

FIGURE 9: Continued. 

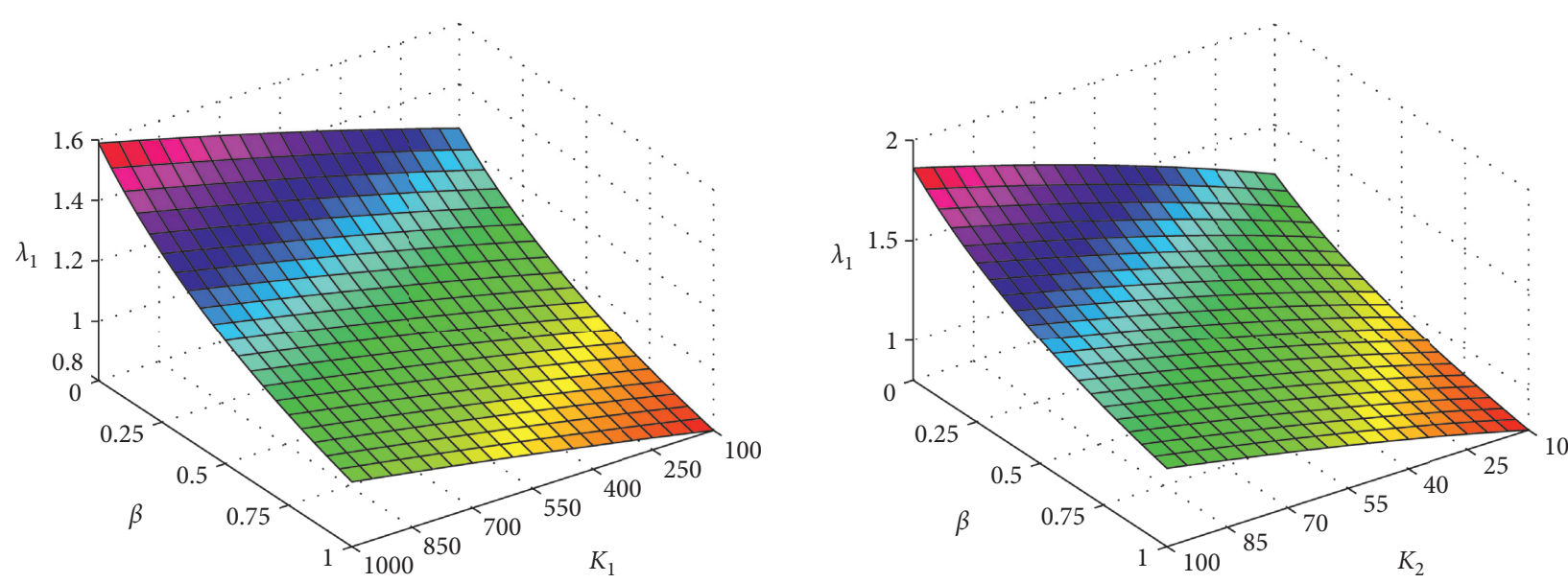

(c)

Figure 9: Nondimensional frequencies of FGP plate with different $K_{1}, K_{2}$, and $\beta$. (a) Case 1; (b) Case 2; and (c) Case 3.

TABLE 7: Nondimensional frequencies of the FGP plate as a function of $k$ and $\Omega$.

\begin{tabular}{|c|c|c|c|c|c|c|c|c|c|c|}
\hline \multirow{3}{*}{$\Omega$} & \multicolumn{5}{|c|}{ SSSS } & \multicolumn{5}{|c|}{ CCCC } \\
\hline & & & $k$ & & & & & $k$ & & \\
\hline & 0 & 2.5 & 5 & 7.5 & 10 & 0 & 2.5 & 5 & 7.5 & 10 \\
\hline \multicolumn{11}{|l|}{ Case 1} \\
\hline 0 & 0.6146 & 0.8460 & 0.9468 & 1.0184 & 1.0706 & 1.0275 & 1.2153 & 1.3432 & 1.4571 & 1.5444 \\
\hline 0.25 & 0.6584 & 0.8830 & 0.9777 & 1.0469 & 1.0984 & 1.0935 & 1.2518 & 1.3694 & 1.4783 & 1.5633 \\
\hline 0.5 & 0.7126 & 0.9238 & 1.0105 & 1.0767 & 1.1273 & 1.1732 & 1.2869 & 1.3930 & 1.4958 & 1.5780 \\
\hline 0.75 & 0.7820 & 0.9677 & 1.0446 & 1.1070 & 1.1564 & 1.2711 & 1.3154 & 1.4102 & 1.5061 & 1.5848 \\
\hline 1 & 0.8745 & 1.0105 & 1.0776 & 1.1357 & 1.1836 & 1.3924 & 1.3226 & 1.4130 & 1.5021 & 1.5766 \\
\hline \multicolumn{11}{|l|}{ Case 2} \\
\hline 0 & 0.6146 & 0.8460 & 0.9468 & 1.0184 & 1.0706 & 1.0275 & 1.2153 & 1.3432 & 1.4571 & 1.5444 \\
\hline 0.25 & 0.6609 & 0.8604 & 0.9563 & 1.0288 & 1.0833 & 1.0977 & 1.2011 & 1.3156 & 1.4273 & 1.5162 \\
\hline 0.5 & 0.7162 & 0.8685 & 0.9569 & 1.0299 & 1.0871 & 1.1707 & 1.1651 & 1.2611 & 1.3675 & 1.4564 \\
\hline 0.75 & 0.7777 & 0.8600 & 0.9357 & 1.0073 & 1.0671 & 1.2179 & 1.0868 & 1.1556 & 1.2496 & 1.3342 \\
\hline 1 & 0.7852 & 0.7972 & 0.8420 & 0.9009 & 0.9580 & 1.0347 & 0.9106 & 0.9310 & 0.9904 & 1.0547 \\
\hline \multicolumn{11}{|l|}{ Case 3} \\
\hline 0 & 0.6146 & 0.8460 & 0.9468 & 1.0184 & 1.0706 & 1.0275 & 1.2153 & 1.3432 & 1.4571 & 1.5444 \\
\hline 0.25 & 0.6609 & 0.9413 & 1.0475 & 1.1196 & 1.1714 & 1.0977 & 1.3661 & 1.5012 & 1.6147 & 1.6994 \\
\hline 0.5 & 0.7162 & 1.0785 & 1.1908 & 1.2621 & 1.3122 & 1.1707 & 1.5836 & 1.7243 & 1.8317 & 1.9084 \\
\hline 0.75 & 0.7777 & 1.3066 & 1.4256 & 1.4917 & 1.5363 & 1.2179 & 1.9297 & 2.0656 & 2.1484 & 2.2018 \\
\hline 1 & 0.7852 & 1.8589 & 1.9631 & 1.9772 & 1.9807 & 1.0347 & 2.4083 & 2.4138 & 2.3588 & 2.3246 \\
\hline
\end{tabular}

$\omega^{*}=\left(\omega a^{2} / h\right) \sqrt{\left(\rho_{b} / E_{b}\right)}$. The first nondimensional frequencies of present work compared with [18] are shown in Table 2.

\section{Numerical Results and Discussions}

For free vibration problems, a fully simple support (SSSS) FGP plate is considered, wherein $a=b, \quad h=a / 10, \quad \Omega=0.5, k=1, E_{t}=10 E_{b}, \rho_{t}=10 \rho_{b}$, $v=0.38$, and $\mu_{F}=0.5$. The first six nondimensional frequencies of the FGP plate with porosity distribution of Case 1 and stiffener of foundation $K_{1}=100, K_{2}=10$ are shown in Table 3; and the first six mode shapes are presented in Figure 6. The stiffness factors and nondimensional frequencies of FGP plate are shown in equation (58) with $H_{b}=\left(E_{b} h^{3} / 12\left(1-v^{2}\right)\right)$.

6.1. Influence of the Parameters of the EFTIM to the Free Vibration for the FGP Plate. Firstly, in order to investigate the effect of the featured-index of the mass of foundation $\beta$ to free vibration of the FGP plate, the featured-index of mass is changed from 0 to 1 . In Figure 7 and Table 4, it is seen that all cases of porosity distribution featured-index of the mass of foundation $\beta$ significantly influence to free vibration of the FGP plate. As $\beta$ increases, the mass of the plate increases, and the frequencies of the plate decrease. For all cases of porosity distribution of the FGP plate, the porosity distribution of 

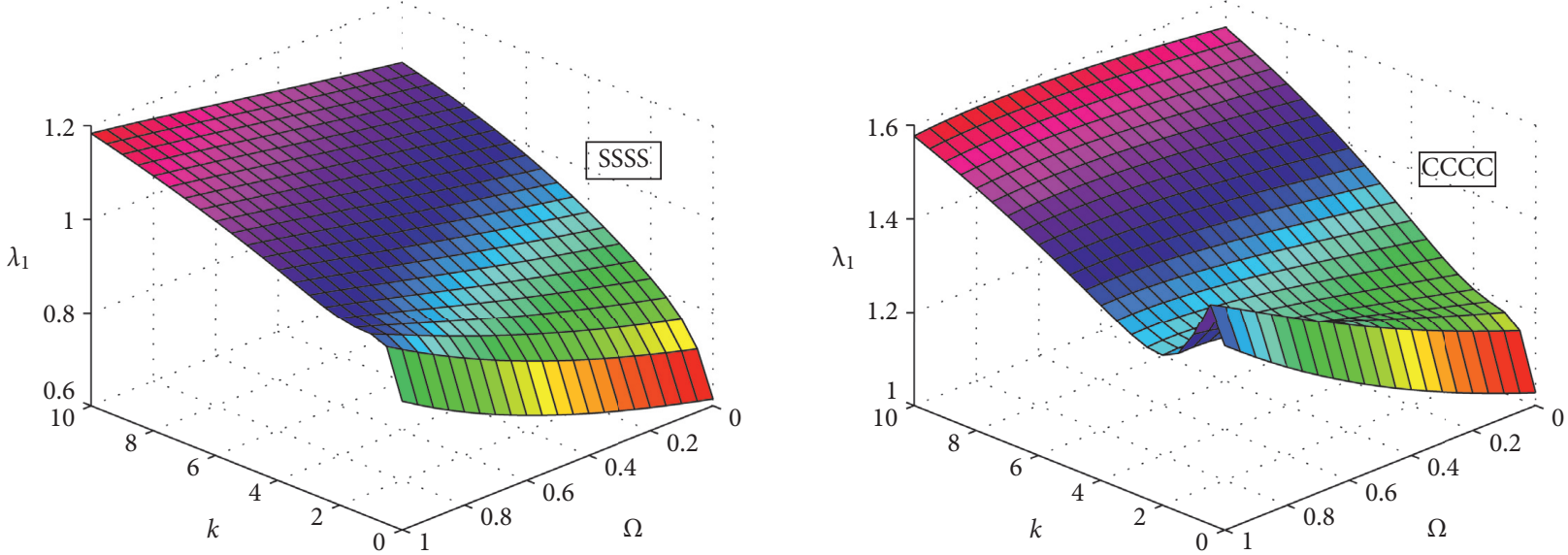

(a)
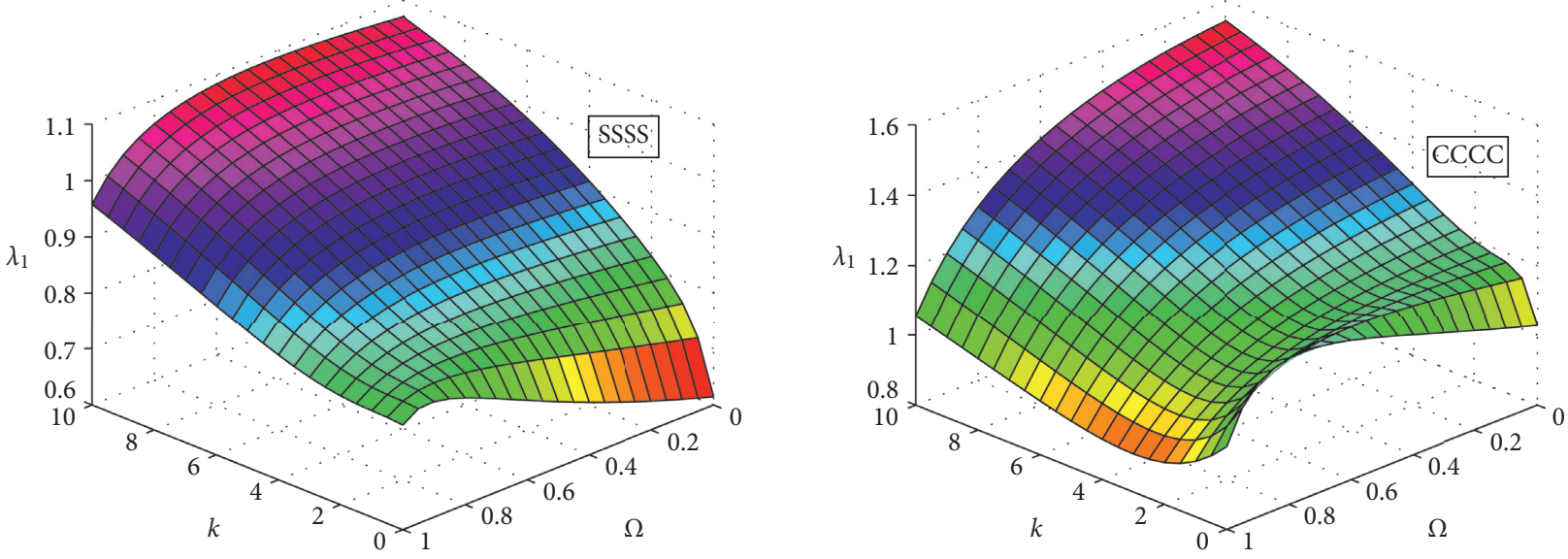

(b)
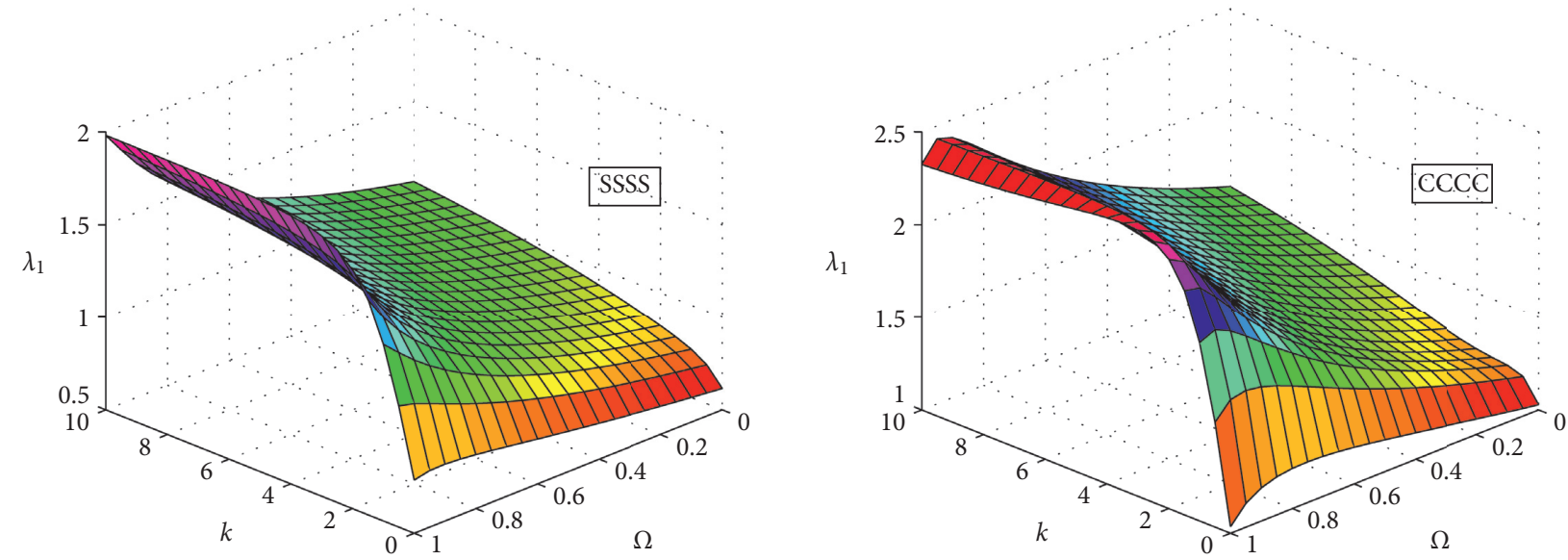

(c)

Figure 10: Nondimensional frequencies vibration of the FGP plate as a function of $k$. (a) Case 1; (b) Case 2; and (c) Case 3.

Case 3 leads to the maximum values of frequencies of the plate, while the porosity distribution of Case 2 leads to the minimum values. It can be observed that the FGP plate with porosity distribution Case 3 is stiffer than plates with other porosity distributions.
Next, the influence of nondimensional parameters of foundation stiffness $K_{1}$ and $K_{2}$ is investigated. We change $K_{1}$ from 100 to 1000 and $K_{2}$ from 10 to 100 with respect to $\beta=0.5$ and $\mu_{F}=0.5$. The first nondimensional frequency of the FGP plate with three cases of porosity distribution is 
presented in Table 5 and shown in Figure 8. As shown in these figure and table, when $K_{1}$ and $K_{2}$ increase, the nondimensional frequency of plate also increases. We also examine the effect of $\left(\beta, K_{1}\right)$ and $\left(\beta, K_{2}\right)$ parameters to nondimensional frequency. The numerical result is presented in Table 6 and Figure 9. Consequently, Winkler foundation stiffness $K_{1}$ and shear layer stiffness of Pasternak foundation $K_{2}$ make stiffness of plate become greater and the mass of the EF involved in the plate's vibration makes reduce frequencies.

6.2. Influence of the Parameters-FGP to Free Vibration of the Plate on EFTIM. Let us consider the effect of materials property to free vibration of the FGP plate. The power-law index $k$ is changed from 0 to 10 , and maximum porosity distributions $\Omega$ has the value from 0 to 1 . We examine the SSSS FGP plate and fully clamped (CCCC) plate resting on EFTIM. The parameters of EFTIM are given by $\beta=0.5$, $\mu_{F}=0.5, K_{1}=100$, and $K_{1}=10$. The first nondimensional frequencies of plate with three cases of porosity distribution is shown in Table 7 and Figure 10.

As shown in these figures and tables, when $k$ and $\Omega$ change, the values of nondimensional frequency change with no rule. It is understandable because with each case of change in porosity distributions $k$ and $\Omega$, the stiffness and the weight of the plate changes. From Figure 10, in the case of the CCCC plate, nondimensional frequency depending on $k$ and $\Omega$ value varies more complex than the case of the SSSS plate. If $k$ and $\Omega$ values are same, the frequency of the CCCC plate is larger than that of the SSSS plate. The results are quite reasonable because the SSSS boundary condition inherently offers more flexible boundary conditions than the CCCC boundary condition.

\section{Conclusions}

In this paper, new numerical results of free vibration of the FGP plate resting on EFTIM are studied. We used the ESMITC3 to establish the fundamental equation of the FGP plate. The computed results obtained by this approach are in excellent agreement with others published. Our work has the following advantages.

The novel ES-MITC3 which computes the free vibration of the plate on EF takes into account the mass of foundation.

The numerical results obtained by ES-MITC3 show good agreement with the reference solutions and are more accurate than those obtained by the original MITC3.

The elastic foundation of Pasternak with three-parameters is developed by adding the featured-index of mass $\beta$ to accurately describe the actual elastic foundation.

The mass of the elastic foundation involved in the vibration of the plate reduces the frequency of vibration, while two parameters $K_{1}$ and $K_{2}$ effect the stiffness of the plate.

The material parameters $k, \Omega$ and the case of porosity distribution effect of vibration of the plate. $\mathrm{Nu}$ merical results are useful for calculation, design, and testing of material parameters in engineering and technologies.
This study suggests some further works on the dynamic response and heat transfer problems of the FGP plate resting on EF using different plate theories.

\section{Data Availability}

The data used to support the findings of this study are included within the article.

\section{Conflicts of Interest}

The authors declare that they have no conflicts of interest.

\section{Acknowledgments}

This research was funded by the Vietnam National Foundation for Science and Technology Development (NAFOSTED) under Grant no. 107.02-2019.330.

\section{References}

[1] E. Winkler, Die Lehre von der Elasticitaet und Festigkeit, Prag, Dominicus, 1867.

[2] P. L. Pasternak, On a New Method of Analysis of an Elastic Foundation by Means of Two Foundation Constants, Gosudarstvennoe Izdatelstvo Literaturi po Stroitelstvu i Arkhitekture, Moscow, Russia, in Russian, 1954.

[3] F. A. Fazzolari, "Generalized exponential, polynomial and trigonometric theories for vibration and stability analysis of porous FG sandwich beams resting on elastic foundations," Composites Part B: Engineering, vol. 136, pp. 254-271, 2018.

[4] A. W. Leissa, "The free vibration of rectangular plates," Journal of Sound and Vibration, vol. 31, no. 3, pp. 257-293, 1973.

[5] Y. Xiang, C. M. Wang, and S. Kitipornchai, "Exact vibration solution for initially stressed mindlin plates on Pasternak foundations," International Journal of Mechanical Sciences, vol. 36, no. 4, pp. 311-316, 1994.

[6] M. H. Omurtag, A. Özütok, A. Y. Aköz, and Y. Özçelikörs, "Free vibration analysis of Kirchhoff plates resting on elastic foundation by mixed finite element formulation based on Gâteaux differential," International Journal for Numerical Methods in Engineering, vol. 40, no. 2, pp. 295-317, 1997.

[7] K. Y. Özçelikörs, C. M. Wang, and X. Q. He, "Canonical exact solutions for Levy-plates on two-parameter foundation using Green's functions," Engineering Structures, vol. 22, no. 4, pp. 364-378, 2000.

[8] H. Matsunaga, "Vibration and stability of thick plates on elastic foundations," Journal of Engineering Mechanics, vol. 126, no. 1, pp. 27-34, 2000.

[9] Y. Ayvaz, A. Daloglu, and A. Dogangün, “Application of a modified Vlasov model to earthquake analysis of plates resting on elastic foundations," Journal of Sound and Vibration, vol. 212, no. 3, pp. 499-509, 1998.

[10] H.-S. Shen, J. Yang, and L. Zhang, "Free and forced vibration of Reissner-mindlin plates with free edges resting on elastic foundations," Journal of Sound and Vibration, vol. 244, no. 2, pp. 299-320, 2001.

[11] K. M. Liew, J.-B. Han, Z. M. Xiao, and H. Du, "Differential quadrature method for mindlin plates on Winkler foundations," International Journal of Mechanical Sciences, vol. 38, no. 4, pp. 405-421, 1996. 
[12] K. M. Liew and T. M. Teo, "Differential cubature method for analysis of shear deformable rectangular plates on Pasternak foundations," International Journal of Mechanical Sciences, vol. 44, no. 6, pp. 1179-1194, 2002.

[13] J.-B. Han and K. M. Liew, "Numerical differential quadrature method for Reissner/mindlin plates on two-parameter foundations," International Journal of Mechanical Sciences, vol. 39, no. 9, pp. 977-989, 1997.

[14] D. Zhou, Y. K. Cheung, S. H. Lo, and F. T. K. Au, "Threedimensional vibration analysis of rectangular thick plates on pasternak foundation," International Journal for Numerical Methods in Engineering, vol. 59, no. 10, pp. 1313-1334, 2004.

[15] S. Chucheepsakul and B. Chinnaboon, "An alternative domain/boundary element technique for analyzing plates on two-parameter elastic foundations," Engineering Analysis with Boundary Elements, vol. 26, no. 6, pp. 547-555, 2002.

[16] Ö. Civalek and M. H. Acar, "Discrete singular convolution method for the analysis of mindlin plates on elastic foundations," International Journal of Pressure Vessels and Piping, vol. 84, no. 9, pp. 527-535, 2007.

[17] A. J. M. Ferreira, C. M. C. Roque, A. M. A. Neves, R. M. N. Jorge, and C. M. M. Soares, "Analysis of plates on Pasternak foundations by radial basis functions," Computational Mechanics, vol. 46, no. 6, pp. 791-803, 2010.

[18] D. Shahsavari, M. Shahsavari, Li Li, and B. Karami, "A novel quasi-3D hyperbolic theory for free vibration of FG plates with porosities resting on Winkler/Pasternak/Kerr foundation," Aerospace Science and Technology, vol. 72, pp. 134-149, 2018.

[19] A. Zenkour and A. Radwan, "Free vibration analysis of multilayered composite and soft core sandwich plates resting on Winkler-Pasternak foundations," Journal of Sandwich Structures \& Materials, vol. 20, no. 2, pp. 169-190, 2018.

[20] N. D. Duc, D. H. Bich, and P. H. Cong, "Nonlinear thermal dynamic response of shear deformable FGM plates on elastic foundations," Journal of Thermal Stresses, vol. 39, no. 3, pp. 278-297, 2016.

[21] A. Mahmoudi, S. Benyoucef, A. Tounsi, A. Benachour, E. A. Adda Bedia, and S. Mahmoud, "A refined quasi-3D shear deformation theory for thermo-mechanical behavior of functionally graded sandwich plates on elastic foundations," Journal of Sandwich Structures \& Materials, vol. 21, no. 6, pp. 1906-1929, 2019.

[22] N. D. Duc, J. Lee, T. Nguyen-Thoi, and P. T. Thang, "Static response and free vibration of functionally graded carbon nanotube-reinforced composite rectangular plates resting on Winkler-Pasternak elastic foundations," Aerospace Science and Technology, vol. 68, pp. 391-402, 2017.

[23] P.-T. Thang, T. Nguyen-Thoi, and J. Lee, "Closed-form expression for nonlinear analysis of imperfect sigmoid-FGM plates with variable thickness resting on elastic medium," Composite Structures, vol. 143, pp. 143-150, 2016.

[24] T. Banh-Thien, H. Dang-Trung, L. Le-Anh, V. Ho-Huu, and T. Nguyen-Thoi, "Buckling analysis of non-uniform thickness nanoplates in an elastic medium using the isogeometric analysis," Composite Structures, vol. 162, pp. 182-193, 2017.

[25] J. Kim, K. K. Żur, and J. N. Reddy, "Bending, free vibration, and buckling of modified couples stress-based functionally graded porous micro-plates," Composite Structures, vol. 209, pp. 879-888, 2019.

[26] S. Coskun, J. Kim, and H. Toutanji, "Bending, free vibration, and buckling analysis of functionally graded porous microplates using a general third-order plate theory," Journal of Composites Science, vol. 3, no. 1, p. 15, 2019.
[27] D. Chen, J. Yang, and S. Kitipornchai, "Elastic buckling and static bending of shear deformable functionally graded porous beam," Composite Structures, vol. 133, pp. 54-61, 2015.

[28] A. S. Rezaei and A. R. Saidi, "Application of Carrera Unified Formulation to study the effect of porosity on natural frequencies of thick porous-cellular plates," Composites Part B: Engineering, vol. 91, pp. 361-370, 2016.

[29] A. S. Rezaei and A. R. Saidi, "Exact solution for free vibration of thick rectangular plates made of porous materials," Composite Structures, vol. 134, pp. 1051-1060, 2015.

[30] J. Zhao, F. Xie, A. Wang, C. Shuai, J. Tang, and Q. Wang, “A unified solution for the vibration analysis of functionally graded porous (FGP) shallow shells with general boundary conditions," Composites Part B: Engineering, vol. 156, pp. 406-424, 2019.

[31] J. Zhao, F. Xie, A. Wang, C. Shuai, J. Tang, and Q. Wang, "Vibration behavior of the functionally graded porous (FGP) doubly-curved panels and shells of revolution by using a semianalytical method," Composites Part B: Engineering, vol. 157, pp. 219-238, 2019.

[32] Q. Li, D. Wu, X. Chen, L. Liu, Y. Yu, and W. Gao, "Nonlinear vibration and dynamic buckling analyses of sandwich functionally graded porous plate with graphene platelet reinforcement resting on Winkler-Pasternak elastic foundation," International Journal of Mechanical Sciences, vol. 148, pp. 596-610, 2018.

[33] S. Sahmani, M. M. Aghdam, and T. Rabczuk, "Nonlocal strain gradient plate model for nonlinear large-amplitude vibrations of functionally graded porous micro/nano-plates reinforced with GPLs," Composite Structures, vol. 198, pp. 51-62, 2018.

[34] D. Wu, A. Liu, Y. Huang, Y. Huang, Y. Pi, and W. Gao, "Dynamic analysis of functionally graded porous structures through finite element analysis," Engineering Structures, vol. 165, pp. 287-301, 2018.

[35] P. T. Thang, T. Nguyen-Thoi, D. Lee, J. Kang, and J. Lee, "Elastic buckling and free vibration analyses of porous-cellular plates with uniform and non-uniform porosity distributions," Aerospace Science and Technology, vol. 79, pp. 278-287, 2018.

[36] G. R. Liu, T. Nguyen-Thoi, and K. Y. Lam, "An edge-based smoothed finite element method (ES-FEM) for static, free and forced vibration analyses of solids," Journal of Sound and Vibration, vol. 320, no. 4-5, pp. 1100-1130, 2009.

[37] T. Nguyen-Thoi, G. R. Liu, and H. Nguyen-Xuan, "An $n$-sided polygonal edge-based smoothed finite element method (nESFEM) for solid mechanics," International Journal for $\mathrm{Nu}$ merical Methods in Biomedical Engineering, vol. 27, no. 9, pp. 1446-1472, 2011.

[38] T. Nguyen-Thoi, G. R. Liu, H. C. Vu-Do, and H. NguyenXuan, "An edge-based smoothed finite element method for visco-elastoplastic analyses of $2 \mathrm{D}$ solids using triangular mesh," Computational Mechanics, vol. 45, no. 1, pp. 23-44, 2009.

[39] H. Nguyen-Xuan, G. R. Liu, T. Nguyen-Thoi, and C. NguyenTran, "An edge-based smoothed finite element method (ESFEM) for analysis of two-dimensional piezoelectric structures," Smart Materials and Structures, vol. 18, p. 12, 2009.

[40] T. N. Thanh, G. R. Liu, H. Nguyen-Xuan, and T. NguyenThoi, "An edge-based smoothed finite element method for primal-dual shakedown analysis of structures," International Journal for Numerical Methods in Engineering, vol. 82, no. 7, pp. 917-938, 2010.

[41] T. Nguyen-Thoi, P. Phung-Van, T. Rabczuk, H. NguyenXuan, and C. Le-Van, "An application of the ES-FEM in solid 
domain for dynamic analysis of 2D fluid-solid interaction problems," International Journal of Computational Methods, vol. 10, no. 1, Article ID 1340003, 2013.

[42] T. Nguyen-Thoi, P. Phung-Van, V. Ho-Huu, and L. Le-Anh, "An edge-based smoothed finite element method (ES-FEM) for dynamic analysis of 2D Fluid-Solid interaction problems," KSCE Journal of Civil Engineering, vol. 19, no. 3, pp. 641-650, 2015.

[43] C. V. Le, H. Nguyen-Xuan, H. Askes, T. Rabczuk, and T. Nguyen-Thoi, "Computation of limit load using edge-based smoothed finite element method and second-order cone programming," International Journal of Computational Methods, vol. 10, no. 1, Article ID 1340004, 2013.

[44] H. Nguyen-Xuan, L. V. Tran, T. Nguyen-Thoi, and H. C. VuDo, "Analysis of functionally graded plates using an edgebased smoothed finite element method," Composite Structures, vol. 93, no. 11, pp. 3019-3039, 2011.

[45] H. H. Phan-Dao, H. Nguyen-Xuan, C. Thai-Hoang, T. Nguyen-Thoi, and T. Rabczuk, "An edge-based smoothed finite element method for analysis of laminated composite plates," International Journal of Computational Methods, vol. 10, no. 1, Article ID 1340005, 2013.

[46] P.-S. Lee and K.-J. Bathe, "Development of MITC isotropic triangular shell finite elements," Computers \& Structures, vol. 82, no. 11-12, pp. 945-962, 2004.

[47] T. Chau-Dinh, Q. Nguyen-Duy, and H. Nguyen-Xuan, "Improvement on MITC3 plate finite element using edgebased strain smoothing enhancement for plate analysis," Acta Mechanica, vol. 228, no. 6, pp. 2141-2163, 2017.

[48] T.-K. Nguyen, V.-H. Nguyen, T. Chau-Dinh, T. P. Vo, and H. Nguyen-Xuan, "Static and vibration analysis of isotropic and functionally graded sandwich plates using an edge-based MITC3 finite elements," Composites Part B: Engineering, vol. 107, pp. 162-173, 2016.

[49] Q.-H. Pham, T.-V. Tran, T.-D. Pham, and D.-H. Phan, "An edge-based smoothed MITC3 (ES-MITC3) shell finite element in laminated composite shell structures analysis," International Journal of Computational Methods, vol. 15, no. 7, Article ID 1850060, 2018.

[50] Q.-H. Pham, T.-D. Pham, V. T. Quoc, and D.-H. Phan, "Geometrically nonlinear analysis of functionally graded shells using an edge-based smoothed MITC3 (ES-MITC3) finite elements," Engineering with Computers, vol. 33, pp. 114, 2019.

[51] D. Pham-Tien, H. Pham-Quoc, T. Vu-Khac, and N. NguyenVan, "Transient analysis of laminated composite shells using an edge-based smoothed finite element method," in Proceedings of the International Conference on Advances in Computational Mechanics 2017, pp. 1075-1094, Springer, Berlin, Germany, 2018.

[52] K.-U. Bletzinger, M. Bischoff, and E. Ramm, "A unified approach for shear-locking-free triangular and rectangular shell finite elements," Computers \& Structures, vol. 75, no. 3, pp. 321-334, 2000.

[53] T. Nguyen-Thoi, P. Phung-Van, H. Nguyen-Xuan, and C. Thai-Hoang, "A cell-based smoothed discrete shear gap method using triangular elements for static and free vibration analyses of Reissner-Mindlin plates," International Journal for Numerical Methods in Engineering, vol. 91, no. 7, pp. 705-741, 2012.

[54] K.-J. Bathe and E. N. Dvorkin, "A formulation of general shell elements-the use of mixed interpolation of tensorial components," International Journal for Numerical Methods in Engineering, vol. 22, no. 3, pp. 697-722, 1986. 